\title{
Brain Activity Mapping in Mecp2 Mutant Mice Reveals Functional Deficits in Forebrain Circuits, Including Key Nodes in the Default Mode Network, that are Reversed with Ketamine Treatment
}

\author{
Miriam Kron,${ }^{\star}$ C. James Howell, ${ }^{\star}$ Ian T. Adams, Michael Ransbottom, Diana Christian, Michael Ogier, \\ and David M. Katz \\ Department of Neurosciences, Case Western Reserve University School of Medicine, Cleveland, Ohio 44106
}

Excitatory-inhibitory imbalance has been identified within specific brain microcircuits in models of Rett syndrome (RTT) and other autism spectrum disorders (ASDs). However, macrocircuit dysfunction across the RTT brain as a whole has not been defined. To approach this issue, we mapped expression of the activity-dependent, immediate-early gene product Fos in the brains of wild-type (Wt) and methyl-CpG-binding protein 2 (Mecp2)-null (Null) mice, a model of RTT, before and after the appearance of overt symptoms ( 3 and 6 weeks of age, respectively). At 6 weeks, Null mice exhibit significantly less Fos labeling than Wt in limbic cortices and subcortical structures, including key nodes in the default mode network. In contrast, Null mice exhibit significantly more Fos labeling than Wt in the hindbrain, most notably in cardiorespiratory regions of the nucleus tractus solitarius (nTS). Using nTS as a model, whole-cell recordings demonstrated that increased Fos expression in Nulls at 6 weeks of age is associated with synaptic hyperexcitability, including increased frequency of spontaneous and miniature EPSCs and increased amplitude of evoked EPSCs in Nulls. No such effect of genotype on Fos or synaptic function was seen at 3 weeks. In the mutant forebrain, reduced Fos expression, as well as abnormal sensorimotor function, were reversed by the NMDA receptor antagonist ketamine. In light of recent findings that the default mode network is hypoactive in autism, our data raise the possibility that hypofunction within this meta-circuit is a shared feature of RTT and other ASDs and is reversible.

\section{Introduction}

Rett syndrome (RTT) is a complex autism spectrum disorder caused by loss-of-function mutations in the gene encoding methyl-CpG-binding protein 2 (MeCP2) (Amir et al., 1999), a transcriptional regulatory protein. RTT patients exhibit severe impairments in cognition, motor control, respiratory and autonomic regulation, as well as increased susceptibility to seizures and autistic behaviors (Hagberg et al., 1983; Julu et al., 2001; Steffenburg et al., 2001; Armstrong, 2005; Weese-Mayer et al., 2006; Chahrour and Zoghbi, 2007; Katz et al., 2009). Altered functional connectivity, manifesting as increased or decreased synaptic strength, has been identified in mouse models of autism spectrum disorders (ASDs) (for review, see Shepherd and Katz,

Received May 4, 2012; revised July 31, 2012; accepted Aug. 4, 2012.

Author contributions: M.K., C.J.H., M.O., and D.M.K. designed research; M.K., C.J.H., I.T.A., M.R., and D.C. performed research; M.K., C.J.H., I.T.A., M.R., and D.C. analyzed data; M.K., C.J.H., and D.M.K. wrote the paper.

This work was supported by grants from NINDS (D.M.K.), the International Rett Syndrome Foundation (D.M.K., M.K.) and Autism Speaks (D.M.K.).We thank Dr. Dan Wesson for reading the manuscript, Dr. Roberto Galan for helpful discussions regarding the ketamine experiments, Dr. Diana Kunze for help with the electrophysiology, and Elizabeth Shick and Alex Kreger for their skilled technical assistance.

${ }^{*}$ M.K. and C.J.H. are equally contributing first authors.

The authors declare no competing financial interests.

Correspondence should be addressed to Dr. David M. Katz, Department of Neurosciences, Case Western Reserve University, School of Medicine, 10900 Euclid Avenue, Cleveland, OH 44106. E-mail: david.katz@case.edu.

DOI:10.1523/JNEUROSCI.2159-12.2012

Copyright $\odot 2012$ the authors $\quad 0270-6474 / 12 / 3213860-13 \$ 15.00 / 0$
2011) and in imaging studies of human patients with autism (Haznedar et al., 2000; Kennedy and Courchesne, 2008; Broyd et al., 2009; Monk et al., 2009; Minshew and Keller, 2010; Weng et al., 2010). Studies of RTT mice suggest there may be regional differences in how loss of MeCP2 affects neural circuits (Shepherd and Katz, 2011). For example, hyperexcitability is a widespread feature of brainstem nuclei in the respiratory pattern-generating network, including the medial nucleus tractus solitarius (Kline et al., 2010; Kron et al., 2011), the preBoetzinger complex (Medrihan et al., 2008), the nucleus Kölliker Fuse (Stettner et al., 2007) and the locus ceruleus (Taneja et al., 2009), as well as hippocampus (Moretti et al., 2006; Zhang et al., 2008; Fischer et al., 2009; Calfa et al., 2011; Nelson et al., 2011). On the other hand, excitatory synaptic transmission is reduced in microcircuits within sensory and motor-frontal cortices (Dani et al., 2005; Dani and Nelson, 2009; Wood et al., 2009; Wood and Shepherd, 2010).

Despite these insights into local defects in synaptic pathophysiology, we currently lack an overview of circuit dysfunction in the RTT brain as a whole. Mapping global network dysfunction is especially important in understanding RTT because some of the most disabling features of the disease, such as abnormal cardiorespiratory control, are highly dependent on behavioral state (Weese-Mayer et al., 2008), suggesting that interactions between distant structures, such as the forebrain and brainstem, are abnormal. Although functional imaging studies could shed light on how MeCP2 loss affects neuronal activity patterns across the 
neuraxis, such studies are not considered practical in RTT patients due to their level of impairment and are technically challenging in mice. However, surrogate markers of neuronal depolarization, such as expression of the protein product of the immediate-early gene c-Fos, can be used to map circuits and pathways in the brain on the basis of neural activity (Dragunow and Faull, 1989). Therefore, the present study used Fos mapping, combined with electrophysiology, to compare activity patterns across the brain in wild-type (Wt) and Mecp2 mutant mice. Our data indicate marked and reproducible effects of the Mecp2 Null genotype on activity levels in different brain regions, including hyperexcitability in autonomic reflex pathways in the brainstem and hypoexcitability in key nodes of the default mode network in the forebrain. However, forebrain hypofunction can be reversed by treatment with a sub-psychotomimetic dose of ketamine, which also rescues behavioral dysfunction.

\section{Materials and Methods}

\section{Animals}

Mecp $2^{\text {tm1.1Jae }}$ mice, developed by Dr. R. Jaenisch (Whitehead Institute, Massachusetts Institute of Technology, Cambridge MA; Chen et al., 2001), were purchased from the Mutant Mouse Regional Resource Center (University of California Davis, Davis CA) and maintained on a mixed genetic background (129Sv, C57BL/6, BALB/c) by crossing Mecp $2^{\text {tm1.1Jae }}$ heterozygous females $\left(M e c p 2^{-/+}\right.$, Het) with Mecp $2^{\text {tm1.1Jae }}$ $\mathrm{Wt}$ males $\left(M e c p 2^{+/ y}\right)$. All experimental procedures were approved by the Institutional Animal Care and Use Committee at Case Western Reserve University.

\section{Immunohistochemistry}

Tissue preparation. Three- and 6-week-old male mice, or 11-week-old female mice, were deeply anesthetized by inhalation of isoflurane and perfused transcardially with PBS followed by ice-cold $4 \%$ paraformaldehyde in $0.1 \mathrm{~m}$ phosphate buffer, $\mathrm{pH} 7.4$, within $10 \mathrm{~min}$. The kinetics of Fos protein induction and degradation are such that potential changes resulting from anesthesia would not be detectable within this timeframe (Ferrara et al., 2003). Brains were postfixed in $4 \%$ paraformaldehyde for $2.5 \mathrm{~h}$, cryoprotected in $25 \%$ sucrose overnight, then frozen in 2-methylbutane at $-45^{\circ} \mathrm{C}$ and stored at $-80^{\circ} \mathrm{C}$. Coronal sections were cut at $40 \mu \mathrm{m}$ with a cryostat microtome (Jung Frigocut $2800 \mathrm{~N}$ ) and stored in PBS at $4^{\circ} \mathrm{C}$.

Immunostaining. Free-floating $40 \mu \mathrm{m}$ sections were processed for Fos immunostaining by blocking with $10 \%$ goat serum in dilution buffer (PBS, BSA, $0.3 \%$ Triton X-100) for $1.5 \mathrm{~h}$ and then incubated overnight at room temperature $(20 \pm 2 \mathrm{~h})$ in rabbit polyclonal anti-c-Fos primary antibody (1:3000, Calbiochem) in dilution buffer plus $10 \%$ goat serum. After sequential rinse steps in dilution buffer and PBS, sections were incubated in biotinylated goat anti-rabbit IgG secondary antibody (1: 400 , Vector Labs) in dilution buffer plus $15 \%$ goat serum for $1 \mathrm{~h}$. After rinsing in PBS, sections were incubated in avidin and biotinylated horseradish peroxidase complex (ABC, 1:150, Vector Labs). Finally, sections were developed using the Sigma Fast diaminobenzidine and urea hydrogen peroxide set, mounted on Super Frost Plus slides and coverslipped using VectaShield (Vector Labs). Specificity of Fos immunolabeling was verified by demonstrating that preabsorption of the anti-c-Fos primary antibody with Fos peptide (Calbiochem) eliminated nuclear staining.

To determine whether Fos-positive cells were neurons or astrocytes, a subset of sections were double stained with anti-c-Fos and either mouse anti-MAP2 (1:1000, Sigma) or mouse anti-GFAP (1:1000, Calbiochem), respectively. Regardless of genotype (Wt vs Null), we only observed Fos labeling in neurons expressing the neuronal cytoskeletal protein MAP2 and saw no colocalization with the glial protein marker GFAP (glial fibrillary acidic protein) ( $n=2$ animals per genotype). In addition, a subset of sections were double stained for Fos and either CaMKII (mouse anti-CaMKII, 1:10,000, Abcam), a marker for glutamatergic neurons, or parvalbumin (mouse anti-parvalbumin, 1:1500, Millipore), which is expressed by a subpopulation of GABAergic neurons. Alexa Fluor 488-
Table 1. Quantification of Fos expression in selected brain regions in Null vs Wt mice

\begin{tabular}{lcc}
\hline & Male Wt & Male Null \\
\hline Medulla & $n=7$ & $n=7$ \\
Medial nTS & $106.5 \pm 0.5$ & $326.4 \pm 0.9^{* * *}$ \\
Lateral nTS & $137.9 \pm 0.7$ & $447.9 \pm 2.0^{* * *}$ \\
Commissural nTS & $21.8 \pm 0.2$ & $53.4 \pm 0.5^{*}$ \\
Nucleus retroambiguus & $7.9 \pm 1.2$ & $11.9 \pm 2.2^{\#}$ \\
preBotzinger Complex & $23.6 \pm 7.4$ & $29.1 \pm 4.7$ \\
Pons & $n=5$ & $n=5$ \\
Pontine nucleus & $322.7 \pm 63.7$ & $199.4 \pm 51.5$ \\
Midbrain & $n=5$ & $n=5$ \\
Dorsal PAG & $21.6 \pm 32.8$ & $13.9 \pm 4.7$ \\
Lateral PAG & $53.0 \pm 25.2$ & $35.9 \pm 10.7^{\#}$ \\
Ventral PAG & $39.7 \pm 12.3$ & $25.6 \pm 7.5^{*}$ \\
Forebrain & $n=5$ & $n=5$ \\
Piriform cortex & $266.3 \pm 35.0$ & $124.2 \pm 19.7^{*}$ \\
Nucleus accumbens & $114.4 \pm 22.8$ & $26.8 \pm 7.9^{* *}$ \\
Cingulate cortex & $50.4 \pm 13.08$ & $14.8 \pm 4.8^{*}$ \\
Retrosplenial cortex & $39.7 \pm 10.86$ & $7.4 \pm 1.6^{*}$ \\
Prelimbic cortex & $34.6 \pm 6.81$ & $8.4 \pm 3.6^{* *}$ \\
Infralimbic cortex & $26.6 \pm 3.8$ & $7.0 \pm 2.2^{* *}$ \\
Motor cortex & $19.9 \pm 3.8$ & $3.1 \pm 1.6^{* *}$ \\
Lateral septal nucleus & $48.6 \pm 14.9$ & $11.6 \pm 4.9^{*}$ \\
Hippocampus (CA1 + CA3) & $22.5 \pm 8.3$ & $14.0 \pm 4.6$ \\
Hippocampus (DG) & $14.3 \pm 4.7$ & $9.5 \pm 2.6$ \\
\hline
\end{tabular}

Data are displayed as mean \pm SEM $\left({ }^{*} p<0.05 ;{ }^{* *} p<0.01 ;{ }^{* * *} p<0.001 ;{ }^{*} p<0.15\right)$.

conjugated goat anti-mouse secondary antibody (1:1000, or 1:2000 for CaMKII, Invitrogen) was used with each double stain.

Ketamine injections. Animals were administered ketamine $(8,20$, or $100 \mathrm{mg} / \mathrm{kg}$, i.p.) or an equivalent volume of saline and then returned to their home cage for $90 \mathrm{~min}$. Subsequently, the animals were deeply anesthetized by inhalation of isoflurane, perfused transcardially, and processed for Fos staining as described above.

Data analysis. Sections were visualized and photographed using an AxioSkop2 microscope (Zeiss) equipped with a Quantifire XI microscope camera (Optronics). Fos-positive cells were counted using pointby-point analysis with Neurolucida software (MBF Bioscience). Before analysis, the photomicrographs were coded so that the observers were blinded to the genotype. Cells were counted in every third section through the nTS, and in a representative subset of sections through the other brain regions analyzed. All sections were analyzed twice by two independent and blinded observers, and respective counts were averaged. The nTS was sampled at 12 levels through the rostro-caudal extent of the nucleus and the average counts at each level were then added together to estimate the total number of labeled cells per animal. To define genotype effects on Fos expression, $G^{\star}$ Power 3 power analysis software (Faul et al., 2007) was used to determine group sizes.

\section{Electrophysiology}

Slice preparation. Horizontal brainstem slices were prepared as previously described (Doyle and Andresen, 2001; Kline et al., 2002, 2010) from 3- and 5- to 7-week-old Mecp2 Null and Wt male mice. Animals were deeply anesthetized by inhalation of isoflurane and then decapitated. Brains were removed from the skull and placed in low $\mathrm{Ca}^{2+}$, ice-cold artificial CSF (ACSF) containing the following (in mM): $125 \mathrm{NaCl}, 3 \mathrm{KCl}$, $1.2 \mathrm{NaH}_{2} \mathrm{PO}_{4}, 1 \mathrm{CaCl}_{2}, 1.2 \mathrm{MgSO}_{4}, 2 \mathrm{MgCl}_{2}, 25 \mathrm{NaHCO}_{3}, 10$ D-glucose, and $0.4 \mathrm{~L}$-ascorbic acid, equilibrated to $\mathrm{pH} 7.4$ with $95 \% \mathrm{O}_{2} / 5 \% \mathrm{CO}_{2}$, for 2-5 min. Then, brainstems were dissected, glued on the mounting platform of a vibratome (Leica, VT 1000S), and horizontal sections containing the nucleus tractus solitarius (nTS), including a long segment of the tractus solitarius (TS) were cut at $220-250 \mu \mathrm{m}$. Slices were then transferred to recording ACSF (containing in mM: $125 \mathrm{NaCl}, 3 \mathrm{KCl}, 1.2$ $\mathrm{NaH}_{2} \mathrm{PO}_{4}, 2 \mathrm{CaCl}_{2}, 1.2 \mathrm{MgSO}_{4}, 25 \mathrm{NaHCO}_{3}, 10$ D-glucose, and 0.4 $\mathrm{L}$-ascorbic acid, equilibrated to $\mathrm{pH} 7.4$ with $95 \% \mathrm{O}_{2} / 5 \% \mathrm{CO}_{2}$ ) at $\sim 32{ }^{\circ} \mathrm{C}$ and allowed to recover from the procedure for at least $30 \mathrm{~min}$ before recordings. 


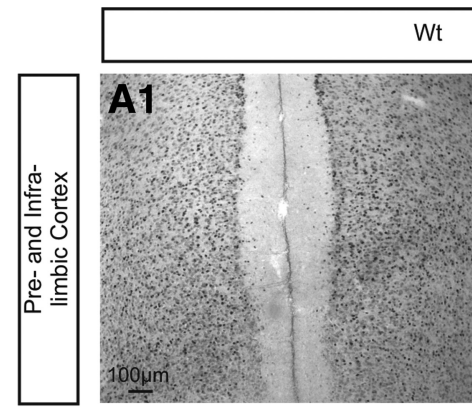

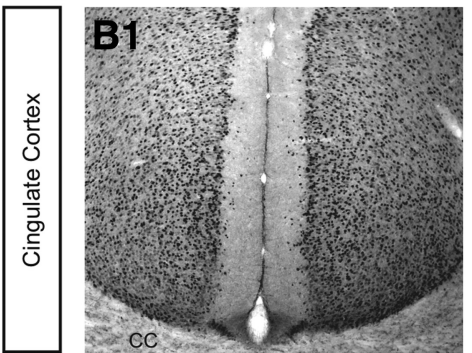
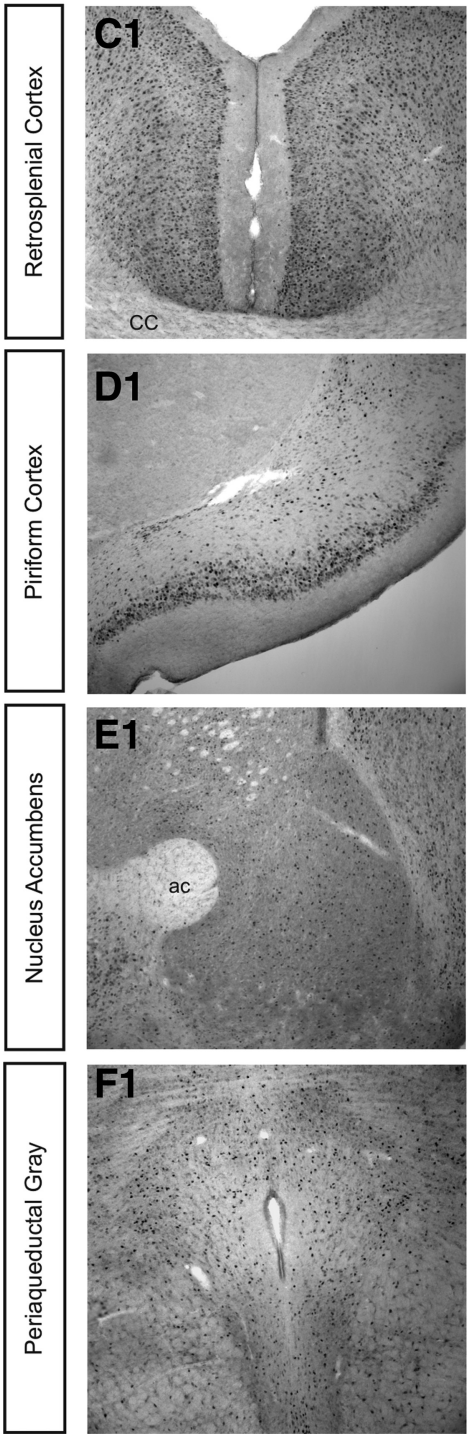
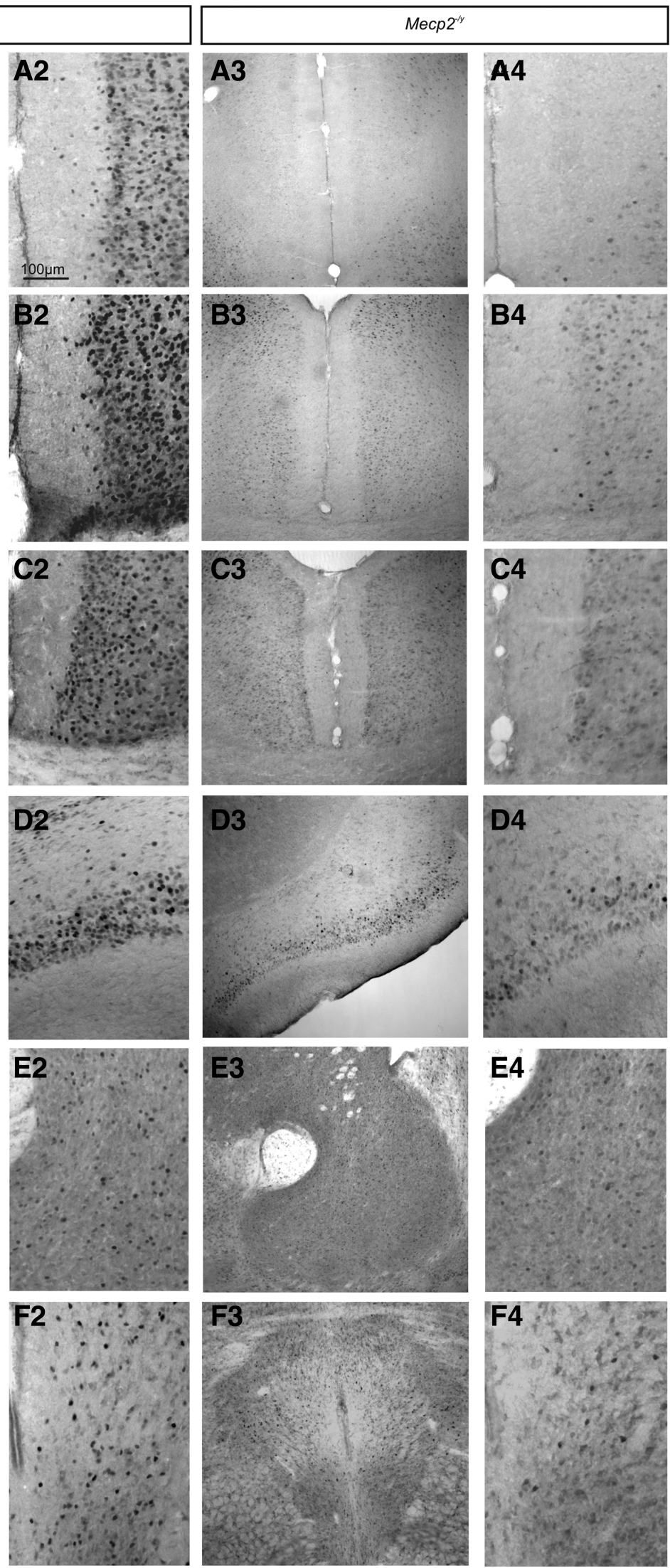

Figure 1. Reduced Fos expression in forebrain and midbrain structures in symptomatic Mecp2 Null mice. At 6 weeks of age, Null mice (A3-F4) exhibit markedly reduced levels of Fos expression in a discrete subset of cortical and subcortical structures, including the prelimbic and infralimbic cortices $(\boldsymbol{A})$, cingulate cortex $(\boldsymbol{B})$, retrosplenial cortex $(\boldsymbol{C})$, piriform cortex $(\boldsymbol{D})$, the nucleus accumbens $(\boldsymbol{E})$, and periaqueductal gray $(\boldsymbol{F})$ compared with Wt $(\boldsymbol{A 1}-\boldsymbol{F 2})$. $\boldsymbol{A} \mathbf{2}-\boldsymbol{F} \mathbf{2}$ and $\boldsymbol{A 4}-\boldsymbol{F 4}$ show higher-magnification views of the sections shown in $\boldsymbol{A} \mathbf{1}-\boldsymbol{F 1}$ and $\boldsymbol{A 3 - F 3}$, respectively. ac, Anterior commissure; cc, corpus callosum. 
A
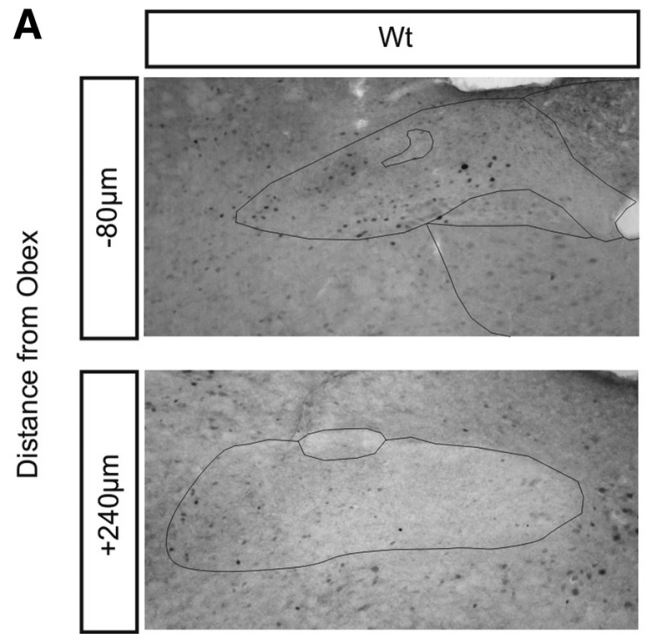

B$$
\text { ब) }
$$

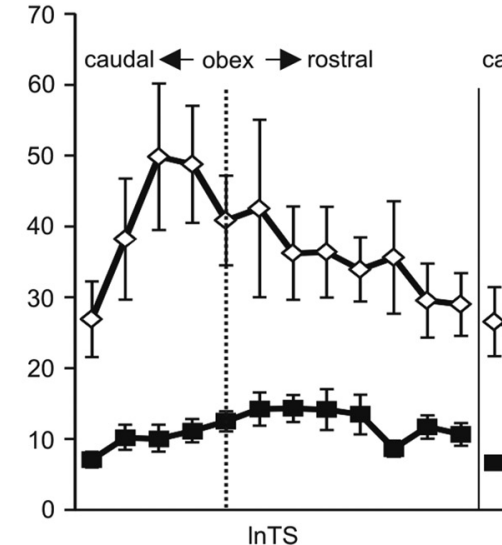

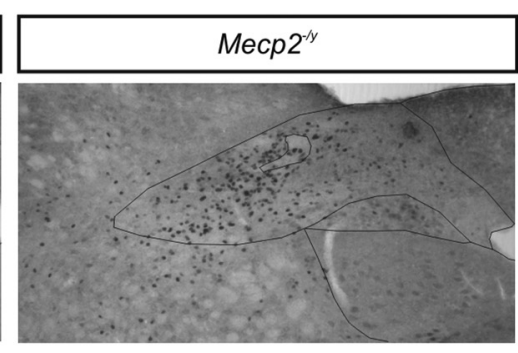
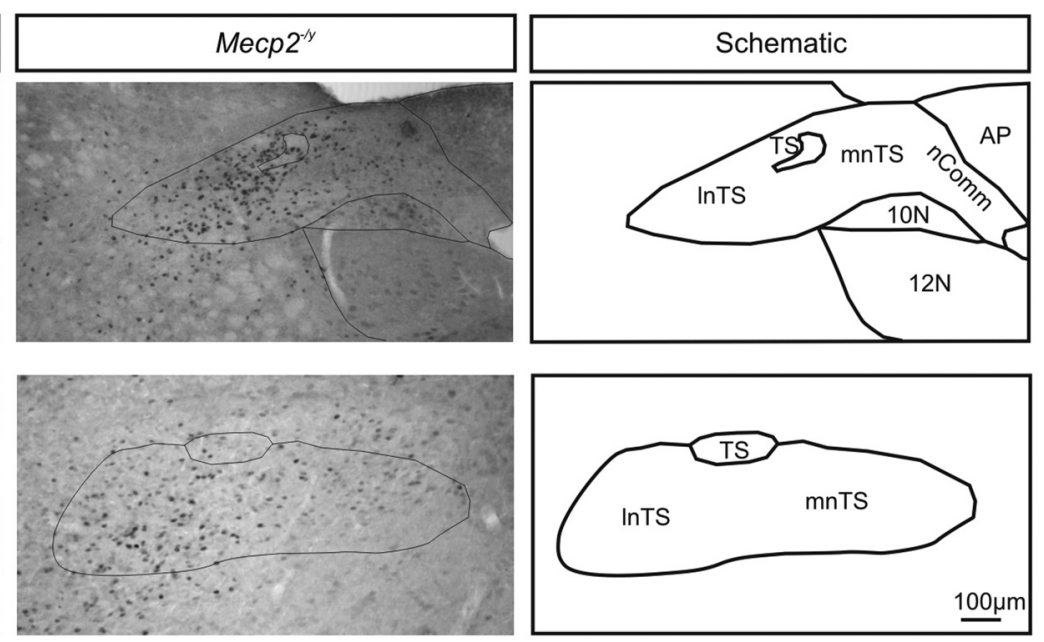

C

Figure 2. Increased Fos expression in the hindbrain nTS in symptomatic Mecp2 Null mice. At 6 weeks of age, Null mice exhibit markedly increased levels of Fos expression in subnuclei within the nucleus tractus solitarius (nTS) of the medulla. $\boldsymbol{A}$, Photomicrographs of representative coronal sections through nTS at 2 different rostrocaudal levels, with a schematic overlay illustrating nTS subnuclei and landmarks. $\boldsymbol{B}$, Quantitative analysis of genotype-dependent differences in Fos expression across the entire rostrocaudal extent of the InTS, mnTS, and nComm subnuclei of nTS in increments of $80 \mu \mathrm{m}$. Note that except for the most anterior and posterior sections through nComm, Fos expression is significantly elevated throughout the rostrocaudal extent of the Null nTS compared with Wt $(p<0.05)$. Dotted lines mark the obex. C, Average counts of Fos-positive cells at each level were combined to provide an estimate of the absolute total number of Fos-positive cells throughout the rostrocaudal extent of nTS in Null vs Wt. 10N, Dorsal motor nucleus of vagus; 12N, hypoglossal nucleus; AP, area postrema; InTS, lateral nTS; mnTS, medial nTS; nComm, commissural nTS; TS, tractus solitarius. ${ }^{*} p<0.05$; ${ }^{* * *} p<0.001$.

Recordings. Slices were placed into the recording chamber, held in place with nylon-wired grid and superfused with recording ACSF at $30-$ $32^{\circ} \mathrm{C}$ at a flow rate of $4-5 \mathrm{ml} / \mathrm{min}$. For stimulation of presynaptic inputs to nTS neurons, a concentric bipolar stimulation electrode (Frederick Haer) was placed on the TS, the medullary tract containing the central axons of cardiorespiratory and other primary afferent inputs to the brainstem, rostral to recording sites. Patch pipettes were pulled from thick-walled borosilicate glass capillaries, and filled with intracellular solution (containing in mM: $130 \mathrm{~K}^{+}$gluconate, $10 \mathrm{NaCl}, 11 \mathrm{EGTA}, 1$ $\mathrm{CaCl}_{2}, 10 \mathrm{HEPES}, 1 \mathrm{MgCl}_{2}, 2 \mathrm{MgATP}, 0.2 \mathrm{NaGTP}$ ), had resistances between 4 and $7 \mathrm{M} \Omega$. Recordings were made within 2 regions of $\mathrm{nTS}$ at the level of, and caudal to the obex: (1) lateral to or within the TS, including the interstitial, lateral and ventrolateral subnuclei [referred to as lateral nTS (lnTS)], (2) within the commissural subnucleus (nComm). Neurons were visualized with an upright Olympus microscope (BX51WIF). Cells were identified as second-order neurons if they received monosynaptic input, defined as a low jitter of latency of evoked postsynaptic responses ( $<250 \mu \mathrm{s})$, at $0.5 \mathrm{~Hz}$ TS stimulation. Evoked, spontaneous and miniature EPSCs (eEPSCs, sPSCs, mEPSCs) were recorded from cells meeting this criterion in the whole-cell voltage-clamp configuration at a holding potential of $-60 \mathrm{mV}$. To record eEPSCs, the TS was stimulated at 0.5 and $20 \mathrm{~Hz}$. In a subset of nComm neurons, input-output curves were obtained by gradually increasing the stimulus intensity based on the neurons' individual threshold (thrsh, thrsh $+10 \%$, thrsh $+50 \%, 2 \times$ thrsh, $5 \times$ thrsh). In all other experiments the stimulation intensity was set to threshold $+10 \%$, typically between 50 and $200 \mu \mathrm{A}$ (stimulus duration $100 \mu \mathrm{s}, 20$ sweeps). To compare intrinsic neuronal excitability between genotypes, action-potential properties and firing frequency in response to current injection (50 pA increments) were recorded in nComm neurons as well. Only neurons with a resting membrane potential of at least $-40 \mathrm{mV}$ upon breakthrough were accepted. Data were acquired using pClamp software. Signals were amplified (Axopatch 200B, Molecular Devices), filtered at $2 \mathrm{kHz}$ and digitized at $10 \mathrm{kHz}$.

Data analysis. Spontaneous and evoked postsynaptic currents were analyzed with Clampfit and Microsoft Excel. In the analysis of eEPSCs, 20 sweeps were averaged with Clampfit and the resulting eEPSC amplitudes were measured and compared between genotypes at different stimulation intensities. For sPSCs and mEPSCs, traces were digitally filtered at 1 $\mathrm{kHz}$, events were counted within 2 min segments, and instantaneous frequencies and amplitudes were analyzed. The detection threshold for sPSCs and mEPSCs was set as $1-1.5 \times$ peak-to-peak noise. Miniature EPSC rise time was analyzed as the time from onset to peak of individual events, and the decay time was estimated as the time between peak and recross of the detection threshold.

\section{Prepulse inhibition}

Prepulse inhibition (PPI) of the acoustic startle response (ASR) was measured to assess sensorimotor gating function using Med Associates Startle Response recording system. Mice were divided into four groups (Het ketamine, Het vehicle, Wt ketamine, Wt vehicle), and received injections 
of either ketamine $(8 \mathrm{mg} / \mathrm{kg})$ or an equivalent amount of saline immediately before they were placed individually inside a small-sized, nonrestrictive, cubical Plexiglas recording chamber [2.5 inches $(\mathrm{L}) \times 2.5$ inches $(\mathrm{W}) \times 1.75$ inches $(\mathrm{H})]$ fixed on an accelerometer platform and allowed to acclimate for $5 \mathrm{~min}$. Subsequently, the mouse was exposed to 4 testing blocks. In the first testing block, the initial startle response amplitude was determined by delivering a $40 \mathrm{~ms}$ pulse of $120 \mathrm{~dB}$ broadband white noise and recording the maximum startle amplitude $\left(V_{\max }\right)$. A baseline startle response was determined by repeating this recording paradigm for six consecutive trials (with $8-23 \mathrm{~s}$ between each stimulus) and calculating the average $V_{\max }$ measured in those trials. In the second and third testing blocks, the mice were exposed to a series of "pulse-only" or "prepulse-pulse pair" stimuli to determine the effect that a reduced intensity prepulse had on the acoustic startle response. The pulse-only stimulus consisted of an $80 \mathrm{~ms}$ stimulus of 120 $\mathrm{dB}$. The prepulse-pulse pair trials were conducted by delivering a single $20 \mathrm{~ms}$ prepulse, with an intensity of 73,76 or $82 \mathrm{~dB}$ before an 80 ms stimulus with an intensity of $120 \mathrm{~dB}$. An average delay of $15 \mathrm{~s}(8-23 \mathrm{~s})$ occurred between each stimulus. Each prepulse-pulse pair trial was repeated 10 times, pulse only trials were repeated 12 times. The $V_{\max }$ measured from each prepulse-pulse trial was compared with the $V_{\max }$ measured from the $120 \mathrm{~dB}$ pulse-only trials, and a percentage prepulse inhibition (\%PPI) was calculated for each prepulse intensity. In the fourth testing block, startle response $V_{\max }$ was recorded from 6 additional $40 \mathrm{~ms}$ pulses of $120 \mathrm{~dB}$ broadband white noise (with $8-23$ s between each stimulus) and compared with the baseline startle response from the first testing block to eliminate the possibility of habituation to the acoustic stimulus throughout the test.

\section{Statistical analysis}

All data are presented as means \pm SEM. Genotype-dependent differences were analyzed by unpaired two-tailed Student's $t$ test. Multiple group data were analyzed by one-way ANOVA with post hoc least significant difference (LSD) test for intergroup comparisons. Miniature EPSC frequency and amplitude distributions were compared with the Kolmogorov-Smirnov test. Results were considered significant if the $p$ value was $<0.05$.

\section{Results}

\section{Fos expression is markedly altered in the Mecp2 Null brain compared with Wt controls}

Fos immunostaining has been widely used as a surrogate marker of neuronal depolarization to map circuits and pathways in the normal brain that are activated by specific types and patterns of neural stimulation (Dragunow and Faull, 1989). Given that excitatory-inhibitory imbalance has been documented within various cell groups in the Mecp2 mutant brain, we hypothesized that Wt and Null animals would exhibit regional differences in Fos expression and that these differences could be used to map sites of circuit dysfunction in the Null brain. To address this possibility, we initially surveyed Fos expression in serial sections throughout the rostro-caudal extent of the brain, from the olfactory bulbs to the spinomedullary junction, in Wt and Null mice at 3 and 6 weeks of age, i.e., before and after the appearance of overt

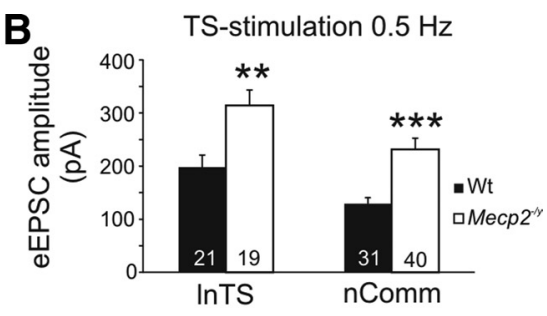

D TS-stimulation $20 \mathrm{~Hz}$
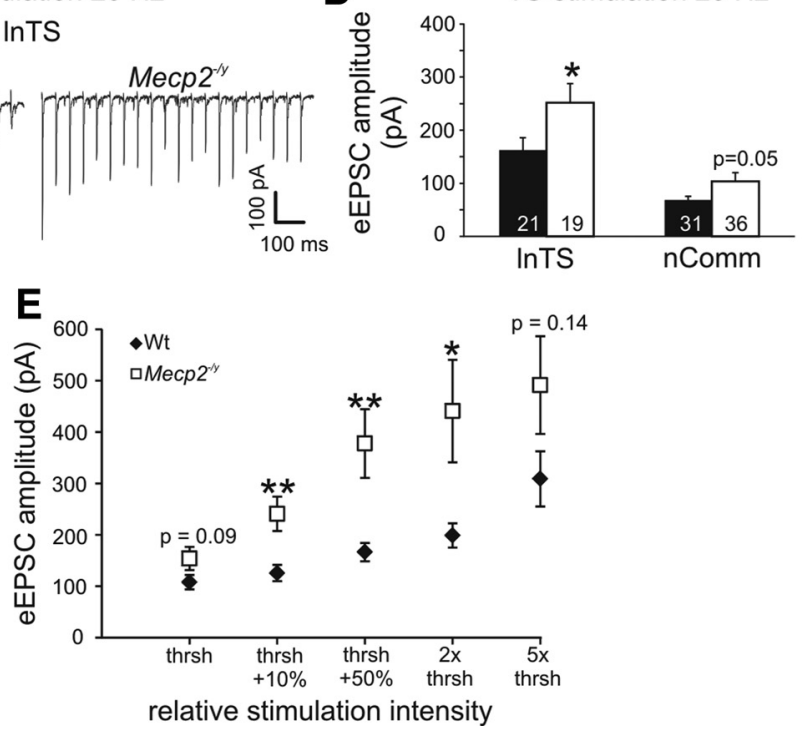

relative stimulation intensity

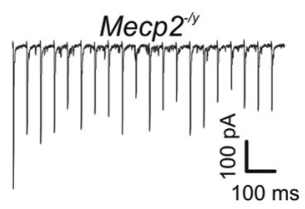

Figure 3. Exaggerated evoked synaptic transmission in the adult Null InTS and nComm. $A$, EPSCS evoked in the InTS by lowtensity, based on the individual neurons' stimulation response threshold, eEPSC amplitudes are larger in Nulls compared with Wt. ${ }^{*} p<0.05 ;{ }^{* *} p<0.01 ;{ }^{* * *} p<0.001$.
Table 2. Membrane properties of second-order nTS relay neurons (nComm)

\begin{tabular}{lcr}
\hline Adult nComm & Wt $(n=49)$ & Null $(n=58)$ \\
\hline$V_{\mathrm{m}}(\mathrm{mV})$ & $-56.1 \pm 1.1$ & $-56.0 \pm 1.0$ \\
$C_{\mathrm{m}}(\mathrm{pF})$ & $24.9 \pm 1.3$ & $25.9 \pm 1.3$ \\
$R_{\mathrm{m}}(\mathrm{M} \Omega)$ & $583.5 \pm 45.3$ & $647.9 \pm 53.0$ \\
\hline
\end{tabular}

Data are displayed as mean \pm SEM.

RTT-like symptoms. We found no obvious effect of Mecp2 genotype on the number of Fos-positive neurons in 3-week-old animals in any brain region examined (postnatal day $21 \pm 3$; Null, $n=4$; Wt, $n=4)$. However, there were marked and reproducible differences between Null and Wt animals at 6 weeks of age across the neuraxis (postnatal day $42 \pm 3$; Null, $n=5-7$; Wt, $n=5-7$; Table 1).

\section{Forebrain}

The most dramatic effects of Mecp2 genotype on Fos expression were observed in cortical and subcortical limbic structures, including the prelimbic and infralimbic cortices, retrosplenial cortex, cingulate cortex, the nucleus accumbens (nAC, both core and shell), as well as the piriform cortex, the motor cortex and lateral septal nuclei, all of which showed significantly less Fos labeling in Null animals compared with Wt (Fig. 1; Table 1). A similar pattern was observed in the auditory, somatosensory, and primary visual cortices, as well as the caudate/putamen. In cortical re- 
Table 3. Membrane properties of second-order nTS relay neurons (InTS)

Data are displayed as mean \pm SEM; ${ }^{*} p<0.05$.

Table 4. Action potential properties of second-order nComm nTS relay neurons

\begin{tabular}{lrr}
\hline AP properties & \multicolumn{1}{c}{ Wt $(n=15)$} & \multicolumn{1}{c}{ Null $(n=16)$} \\
\hline Threshold $(\mathrm{mV})$ & $-31.68 \pm 1.56$ & $-34.24 \pm 1.34$ \\
Rise time $(\mathrm{ms})$ & $0.91 \pm 0.04$ & $0.82 \pm 0.05$ \\
Amplitude $(\mathrm{mV})$ & $76.05 \pm 2.38$ & $74.24 \pm 2.76$ \\
Decay time (ms) & $0.70 \pm 0.02$ & $0.64 \pm 0.03$ \\
AHP (mV) & $-24.33 \pm 1.60$ & $-21.94 \pm 1.26$
\end{tabular}

Data are displayed as mean $\pm \mathrm{SEM} ;{ }^{*} p<0.05 ; \mathrm{AP}$, Action potential; AHP, fast afterhyperpolarization.

Table 5. Action potential firing properties of second-order nComm nTS relay neurons

\begin{tabular}{lll}
\hline \multicolumn{2}{l}{ AP firing frequency in response to current injection } \\
\hline Current injection (pA) & APs/s Wt $(n=12-14)$ & APs/s Null $(n=11-14)$ \\
\hline 50 & $38.14 \pm 4.12$ & $25.14 \pm 3.52^{*}$ \\
100 & $63.14 \pm 4.60$ & $53.71 \pm 4.27$ \\
150 & $78.50 \pm 4.56$ & $72.21 \pm 4.49$ \\
200 & $84.08 \pm 6.81$ & $76.91 \pm 4.74$ \\
\hline
\end{tabular}

Data are displayed as mean \pm SEM; ${ }^{*} p<0.05$. AP, Action potential.

\begin{tabular}{lccccc}
\hline & Juvenile InTS & & & Adult InTS & \\
\cline { 2 - 3 } \cline { 5 - 6 } & Wt $(n=26)$ & Null $(n=30)$ & & Wt $(n=21)$ & Null $(n=18)$ \\
\hline$V_{m}(m V)$ & $-64.5 \pm 2.1$ & $-59.5 \pm 1.4^{*}$ & & $-60.4 \pm 1.8$ & $-62.9 \pm 2.6$ \\
$C_{m}(p F)$ & $37.8 \pm 2.4$ & $36.8 \pm 2.7$ & & $34.6 \pm 3.0$ & $29.9 \pm 1.9$ \\
$R_{m}(m \Omega)$ & $440.6 \pm 60.0$ & $462.0 \pm 75.0$ & & $447.3 \pm 56.3$ & $464.5 \pm 51.5$ \\
\hline
\end{tabular}

gions, genotype effects on Fos labeling did not appear to exhibit any laminar specificity. Quantitative analysis revealed that the number of Fos-positive cells in Nulls was reduced by up to $80 \%$ compared with Wt (\%Wt; piriform cortex, 46.6\%; nAC, 23.4\%; cingulate cortex, 29.4\%; retrosplenial cortex, 18.6\%; prelimbic cortex, $24.3 \%$; infralimbic cortex, $26.3 \%$; motor cortex, $15.6 \%$; lateral septal nucleus, $32.9 \%$; Table 1). No genotypic differences in Fos expression were noted in other forebrain regions, such as the hippocampus, including the dentate gyrus and the CA1 and CA3 regions together (CA; Table 1$)$ nor in the mammillary bodies, thalamus and hypothalamus.

\section{Brainstem and cerebellum}

In the brainstem, the periaqueductal gray (PAG) and the nucleus of the solitary tract (nTS), both of which are major cell groups involved in modulation of autonomic homeostasis (Andresen and Kunze, 1994; Kubin et al., 2006; Subramanian et al., 2008; Subramanian and Holstege, 2010), exhibited the strongest genotypedependent differences in Fos expression levels. Specifically, the Null PAG had significantly fewer Fos-positive cells compared with $\mathrm{Wt}$ (Wt, 38.1 \pm 20.0; Null, $25.1 \pm 6.0 ; p<0.01$; Table 1; Fig. $1 F$ ). This was due primarily to a deficit in the ventral subdivision (vlPAG, reduction of $35.5 \%$; Table 1), whereas Fos-expression was not significantly different between $\mathrm{Wt}$ and Null in the lateral (IPAG) and dorsal divisions (dPAG), despite strong trends toward lower expression in the Nulls (Table 1). In contrast, Null mice exhibited significantly more Fos-positive cells throughout the rostrocaudal extent of the three major cardiorespiratory subnuclei in nTS [medial (mnTS), commissural (nComm) and lateral nTS, including interstitial, lateral and ventrolateral subnuclei (lnTS)] compared with Wt (\%Wt; mnTS; 306.5\%; nComm; 245.0\%, $\operatorname{lnTS}$; 324.8\%; Fig. 2A-C; Table 1). However, no significant genotype-dependent
A
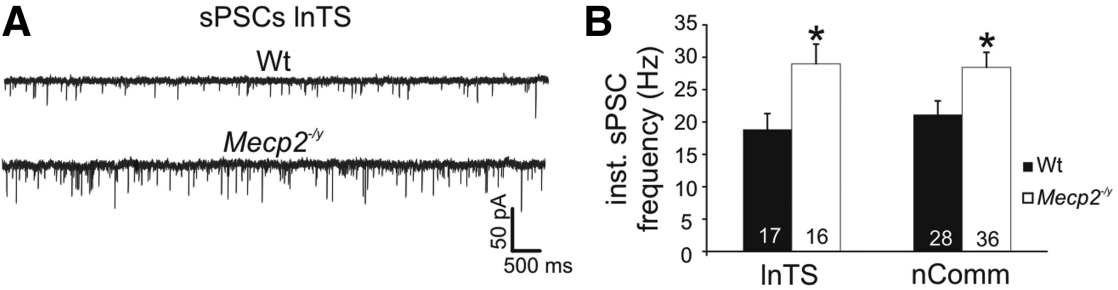

C
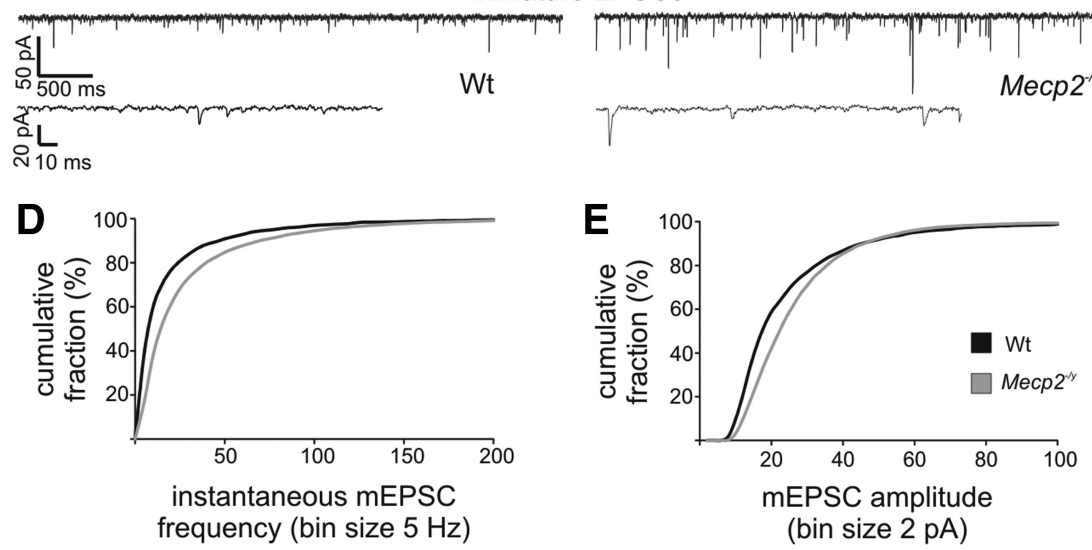

Figure 4. Enhanced spontaneous excitatory currents at primary afferent synapses in the Null nTS compared with Wt. $\boldsymbol{A}$, Representative recordings from a Wt and a Null InTS second-order neuron illustrating higher sPSC frequency in the Nulls. $\boldsymbol{B}$, Group data Wt and a Null InTS second-order neuron at low (top traces) and high (bottom traces) resolution illustrating higher mEPSC frequency and amplitudes in the Nulls. $\boldsymbol{D}, \boldsymbol{E}$, Cumulative mEPSC frequency $(\boldsymbol{D})$ and amplitude $(\boldsymbol{E})$ distribution curves from recordings of $\mathrm{InTS}$ and nComm neurons show right-shifts in the Nulls, indicating higher mEPSC frequencies and amplitudes, respectively, compared with Wt. ${ }^{*} p<0.05$; $^{* *} p<0.01$; ${ }^{* *} p<0.001$. reveal a significantly higher sPSC frequency in both Null InTS and nComm compared with Wt. C, Representative recordings from a effects were found in the nucleus retroambiguus (nRA), the preBotzinger complex (pBC), pontine nucleus, or the cerebellum (Table 1).

\section{Genotype effects on Fos labeling are associated with altered synaptic excitability}

Although Fos has been widely validated as a marker of neural activity in normal animals, this has not previously been analyzed in animals lacking MeCP2. Therefore, to determine whether or not Mecp2 genotype effects on Fos labeling indeed reflect differences in neural activity, patchclamp electrophysiological recordings were used to compare synaptic and neuronal excitability in Wt and Null mice at 5-7 weeks of age, using the nTS as a model system. The nTS is ideally suited for such analyses because of a clear anatomic segregation between presynaptic inputs in the solitary tract (TS) and second-order neurons within the various nTS subnuclei. Indeed, EPSC amplitudes evoked by TS stimulation at $0.5 \mathrm{~Hz}$ (20 sweeps; stimulation intensity at $10 \%$ above the neurons' individual thresholds) were significantly larger in Nulls compared with Wt in both the lnTS and nComm (lnTS; Null, $314.1 \pm 29.3 \mathrm{pA}, n=19$; Wt, 
$198.1 \pm 22.7 \mathrm{pA}, n=21 ; p<0.01$, unpaired Student's $t$ test; nComm; Null, $231.5 \pm 21.1$ $\mathrm{pA}, n=40$; Wt, $129.3 \pm 11.2 \mathrm{pA}, n=31$; $p<0.001$; Fig. $3 A, B)$, consistent with previous findings in the mnTS (Kline et al., 2010). To validate these genotypedependent differences and to facilitate comparisons across individual neurons and between genotypes, threshold-based input-output curves were recorded from a subset of nComm neurons at $0.5 \mathrm{~Hz}$ TS stimulation. These recordings revealed significantly higher eEPSC amplitudes in the Null nComm at the 3 intermediate stimulation intensities and strong trends at the lowest and highest stimulation intensities (Wt, $n=17$; Null, $n=16$; Fig. $3 E$ ). Increasing TS-stimulation frequency to $20 \mathrm{~Hz}$ also revealed significantly larger eEPSC amplitudes in the Null lnTS, and a strong trend in nComm as well (lnTS; Null, $251.8 \pm 35.7$ pA; Wt, $162.6 \pm 23.2$ pA, $p<0.05$; nComm; Null, $103.6 \pm 16.3$ $\mathrm{pA}$; Wt, $68.7 \pm 6.5 \mathrm{pA}, p=0.052$; Fig. $3 C, D)$. Frequency-dependent synaptic depression, a feature of primary afferent synapses in nTS (Doyle and Andresen, 2001; Andresen and Peters, 2008; Kline et al., 2010), was unaffected by Mecp2 genotype in either nComm or lnTS. Similarly, basic membrane properties, including membrane potential $\left(V_{\mathrm{m}}\right)$, membrane capacitance $\left(C_{\mathrm{m}}\right)$ and membrane resistance $\left(R_{\mathrm{m}}\right)$ were comparable between genotypes (Tables 2, 3). Likewise, action-potential properties were similar between the genotypes, and current-induced step depolarization at $-60 \mathrm{mV}$ evoked comparable numbers of APs at all current levels except for $50 \mathrm{pA}$ (the lowest level tested) which evoked fewer APs in Null cells compared with Wt (Tables 4, 5).

To define potential genotype effects on spontaneous network activity in nTS, sPSCs were recorded and analyzed in 2 min intervals. In the lnTS, we detected significantly more events in Nulls compared with Wt (Null, $1165.3 \pm 169.3, n=16$; Wt, $718.1 \pm$ 141.6, $n=17, p<0.05$ ) which resulted in a significantly higher instantaneous frequency (Null, $29.0 \pm 3.1 \mathrm{~Hz}$; Wt, $18.9 \pm 2.4 \mathrm{~Hz}$, $p<0.05$; Fig. $4 A, B)$. Instantaneous sPSC frequency was also increased in the Null nComm compared with Wt (Null, $28.4 \pm$ $2.3 \mathrm{~Hz}, n=36$; Wt, $21.2 \pm 2.1 \mathrm{~Hz}, n=28, p<0.05$; Fig. $4 B$ ), in association with a strong trend toward an increase in the number of spontaneous events (Null, 1231.9 \pm 160.8; Wt, 867.2 \pm $127.3 ; p=0.08)$. Addition of the AMPA-receptor blocker 6-cyano-7-nitroquinoxaline-2,3-dione to the superfusate $(10 \mu \mathrm{M})$ completely abolished sPSCs and reduced eEPSC amplitudes by $92.2 \pm 1.4 \%(n=10)$, indicating that primary afferent transmission in nTS is mainly mediated by AMPA-receptors.

To specifically examine how Mecp2 genotype may affect spontaneous presynaptic release of excitatory transmitter, miniature EPSCs were recorded in the presence of bicuculline (10 $\mu \mathrm{M})$ and TTX $(0.5 \mu \mathrm{M})$ and analyzed in 2 min intervals. Since we found similar genotype effects in the nComm and lnTS, data
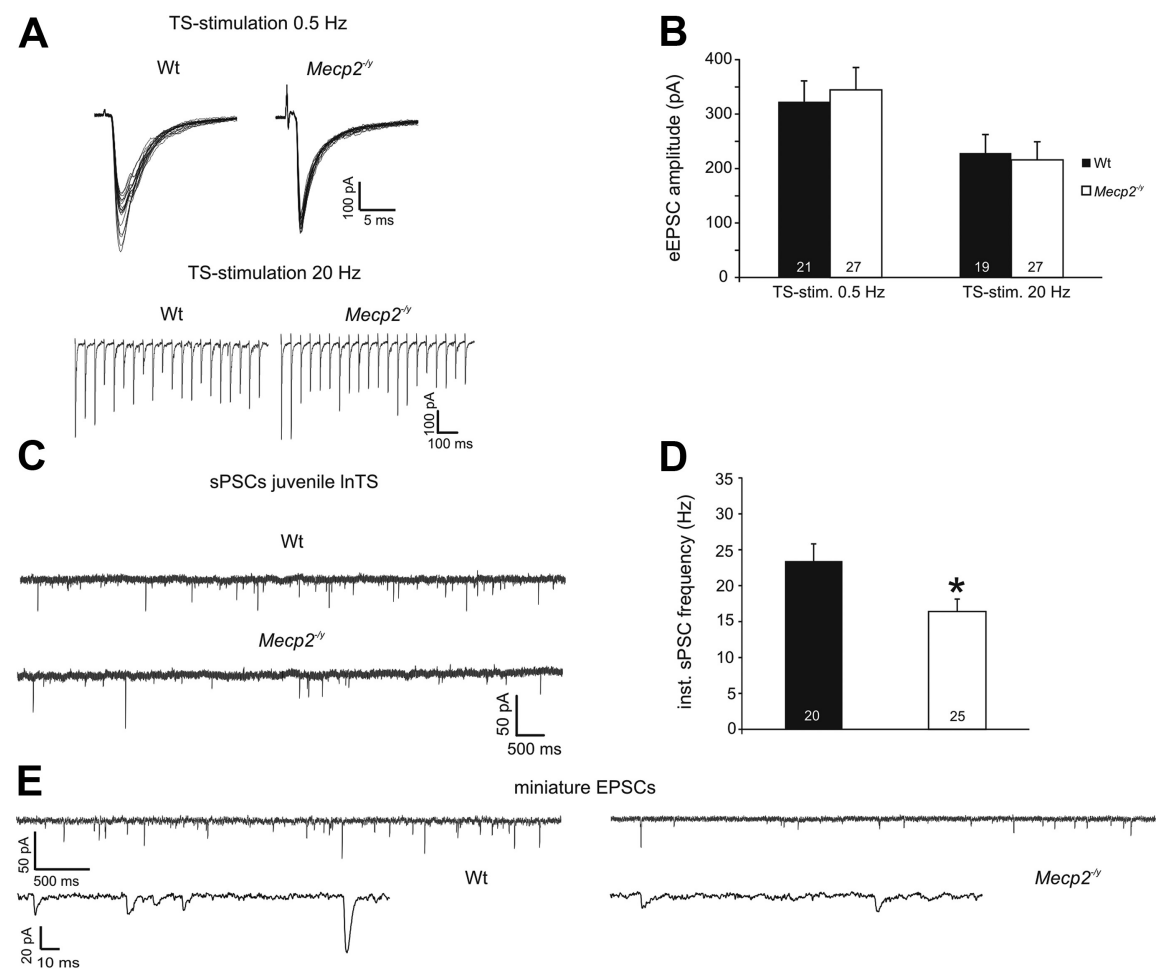

Figure 5. Evoked synaptic transmission is normal in the Null $\mathrm{nTS}$ at 3 weeks of age despite reduced spontaneous excitatory currents. $\boldsymbol{A}, \boldsymbol{B}, 0.5$ and $20 \mathrm{~Hz}$ stimulation both yield similar eEPSC amplitudes in juvenile Wt and Null InTS second-order neurons. $\boldsymbol{C}$, frequency and amplitudes in the NullnTS at 3 weeks. $\boldsymbol{F}, \mathbf{G}$, Cumulative mEPSC frequency $(\boldsymbol{F})$ and amplitude $(\boldsymbol{G})$ distribution curves demonstrate left-shifts in the Nulls at 3 weeks, indicating lower mEPSC frequencies and lower amplitudes, respectively, compared with Wt. ${ }^{*} p<0.05 ;{ }^{* *} p<0.01 ;{ }^{* * *} p<0.001$.

from both subnuclei were pooled. In Nulls, both the number of events and the instantaneous mEPSC frequency were significantly increased compared with Wt (Null, $1006 \pm 162.6$ events, $24.6 \pm 2.9 \mathrm{~Hz}, n=9$; Wt, $461.6 \pm 94.0$ events, $15.9 \pm 2.4 \mathrm{~Hz}, n=$ 7 ; $p$ values $<0.05$; Fig. $4 C, D)$. Accordingly, the cumulative frequency distribution curve showed a significant right shift in the Nulls (Kolmogorov-Smirnov test, $p<0.05$, Fig. $4 D$ ). Moreover, the cumulative mEPSC amplitude distribution curve also displayed a significant right shift in the Nulls, indicating larger mEPSC amplitudes (Kolmogorov-Smirnov test, $p<0.05$, Fig. 4E). We did not observe genotype differences in $\mathrm{MEPSC}$ rise or decay times (rise time; Wt, $1.00 \pm 0.11 \mathrm{~ms}$; Null, $0.91 \pm 0.09 \mathrm{~ms}$; decay time; Wt, $2.91 \pm 0.49 \mathrm{~ms}$; Null, $2.75 \pm 0.36 \mathrm{~ms}$ ).

\section{Elevated Fos expression and synaptic hyperexcitability develop in parallel in Mecp2 Nulls}

Analysis of 6-week-old animals revealed a strong association between elevated Fos expression and synaptic hyperexcitability within specific subnuclei in the Null nTS compared with Wt. To further explore how these two endophenotypes may be linked to each other, and to the onset of disease, we quantified Fos levels 
A

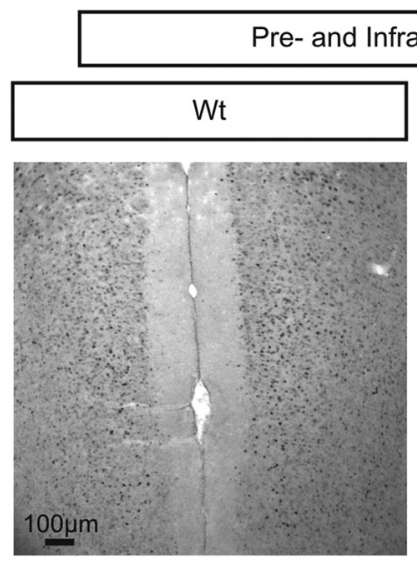

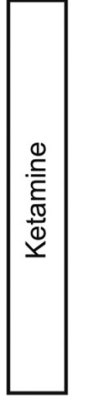
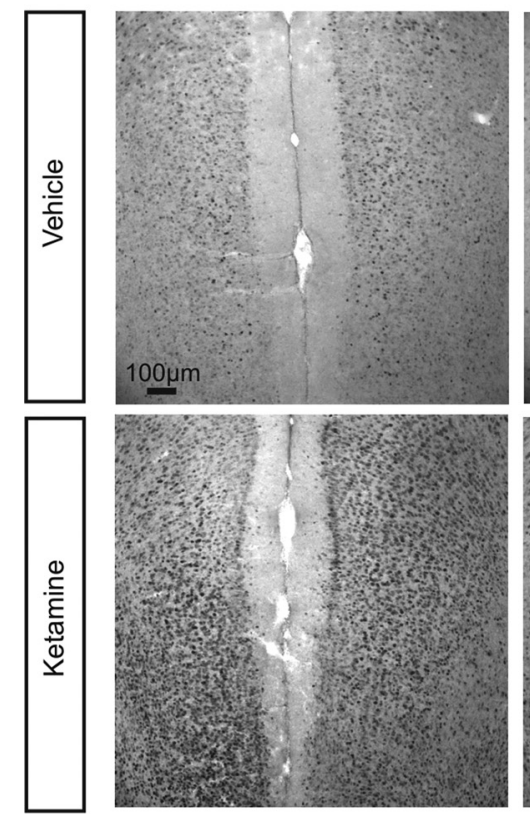
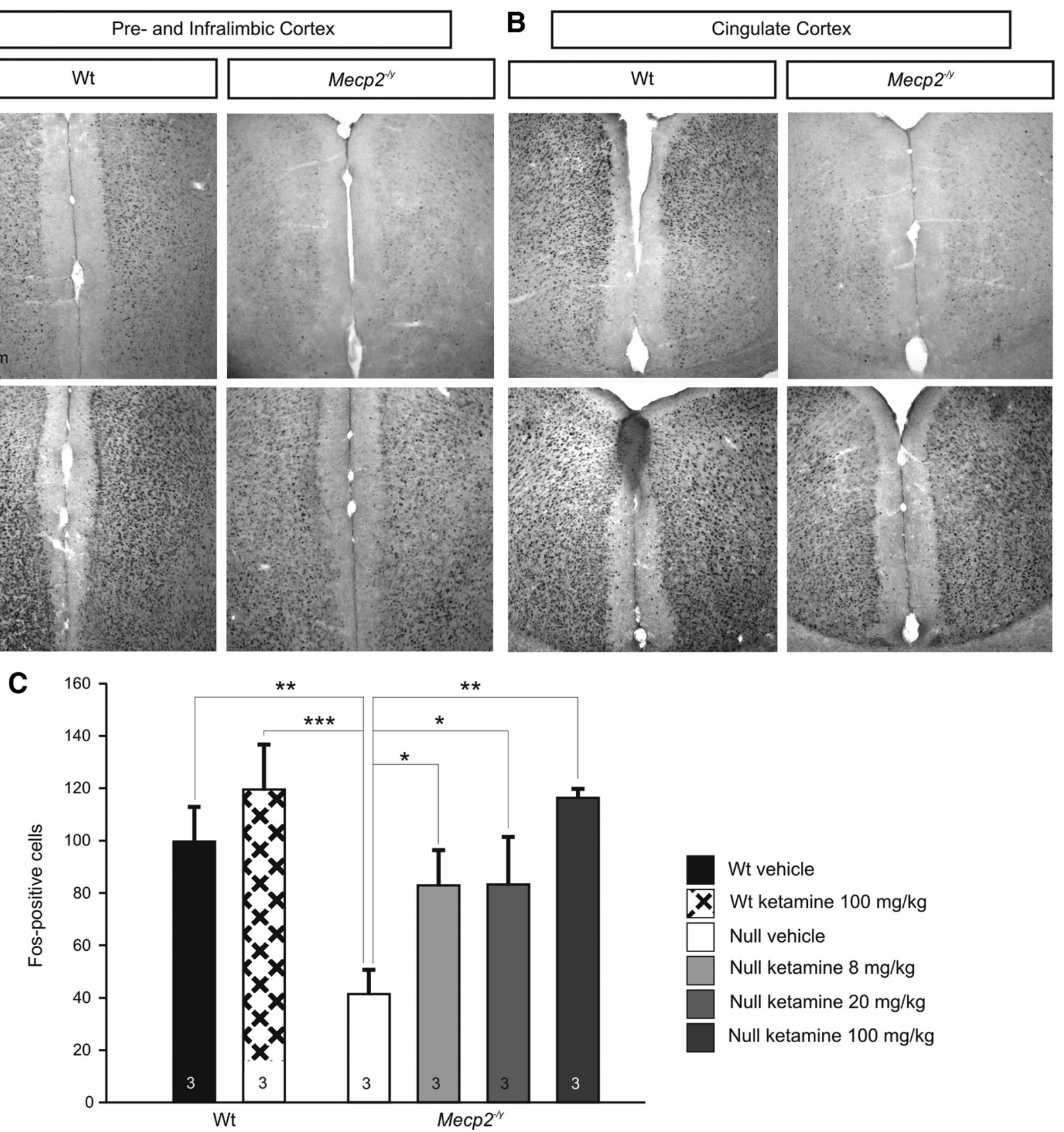

Figure 6. Systemic treatment with ketamine acutely increases Fos expression in the forebrain of Wt and Null mice and reverses the Fos-deficient phenotype in Nulls. $\boldsymbol{A}, \boldsymbol{B}$, Injection of ketamine $(100 \mathrm{mg} / \mathrm{kg}$, i.p.) increases Fos expression throughout the forebrain in Nulls and Wt; representative sections from the prelimbic and infralimbic cortices $(\boldsymbol{A})$ and cingulate cortex (B) are shown. $\boldsymbol{C}$, Ketamine causes a dose-dependent increase in Fos expression levels in Null mice, restoring Fos expression to naive Wt levels as shown here in the piriform cortex. In Wt, $100 \mathrm{mg} / \mathrm{kg}$ ketamine increased the number of Fos-positive cells by $\sim 20 \%$. ${ }^{*} p<0.05$; ${ }^{* *} p<0.01$; ${ }^{* * *} p<0.001$.

and analyzed synaptic excitability in the nTS of 3-week-old mice before the appearance of overt symptoms.

In contrast to 6-week-old animals, Fos was expressed at relatively low levels in the nTS of both Null and Wt animals at 3 weeks, and we saw no significant effect of genotype in any subnucleus of the nTS (Wt, $n=4$; Null, $n=4$; mnTS; Wt, $3.8 \pm 0.5$ cells; Null, $3.5 \pm 0.4$ cells; $\operatorname{lnTS}$; Wt, $4.4 \pm 0.7$ cells; Null, $3.7 \pm 0.7$ cells; nComm; Wt, $3.1 \pm 0.5$ cells; Null, $1.9 \pm 0.2$ cells).

To evaluate genotype effects on synaptic function in nTS at 3 weeks of age, we focused our analysis on the lnTS. With the exception of $V_{\mathrm{m}}$, which was more negative in $\mathrm{Wt}$ neurons, there was no effect of genotype on basic neuronal properties (Table 3). Similarly, there was no effect of genotype on eEPSC amplitudes evoked by TS stimulation at $0.5 \mathrm{~Hz}(\mathrm{Wt}, 322.8 \pm 38.2 \mathrm{pA}, n=21$; Null, $344.4 \pm 41.2$ pA, $n=27$; Fig. $5 A, B)$ or $20 \mathrm{~Hz}$ (Wt, $228.5 \pm$ 34.1 pA; Null, $215.9 \pm 33.3$ pA; Fig. $5 A, B)$. Regardless of genotype, eEPSC amplitudes at 3 weeks of age were comparable to those recorded in Nulls at 6 weeks (see above).

Instantaneous sPSC frequency (Wt, $23.4 \pm 2.4 \mathrm{~Hz}, n=20$; Null, $16.4 \pm 1.7 \mathrm{~Hz}, n=25, p<0.05)$ and number of events (Wt, 877.6 \pm 123.2 ; Null, 545.0 $\pm 81.0, p<0.05$ ) were significantly lower in juvenile Nulls compared with juvenile $\mathrm{Wt}$ (Fig. 5C,D). To compare the spontaneous release of excitatory transmitter between the genotypes in presymptomatic mice in more detail, we constructed mEPSC frequency and amplitude probability distribution plots. In contrast to mEPSC analyses 
from 5- to 7-week-old mice, both frequency and amplitude distribution plots showed a significant left shift in the Nulls (Kolmogorov-Smirnov test, $p<0.05$; Wt, $n=8$; Null, $n=9$; Fig. $5 E-G)$, indicating lower mEPSC frequency and smaller mEPSC amplitudes. Miniature EPSC rise and decay times were comparable between the genotypes (rise time; $\mathrm{Wt}, 0.86 \pm 0.08$ $\mathrm{ms}$; Null, $0.79 \pm 0.09 \mathrm{~ms}$; decay time; Wt, $1.96 \pm 0.15 \mathrm{~ms}$; Null, $2.04 \pm 0.17 \mathrm{~ms})$.

\section{The NMDA receptor antagonist ketamine restores Wt levels of Fos expression in the Null forebrain}

To determine whether or not decreased Fos expression in cortical structures within the adult Null forebrain reflects an intrinsic inability to express Fos in the absence of MeCP2 or, alternatively, results from reduced network activity, we compared the effects of ketamine treatment in Null and Wt mice. Ketamine is an NMDA receptor antagonist that has previously been shown to upregulate Fos expression in the limbic forebrain of mice and rats (Nakao et al., 2002, 2003; Inta et al., 2009) by disinhibiting cortical pyramidal cells (Nakao et al., 2003; Behrens et al., 2007). Indeed, acute treatment with ketamine ( $8 \mathrm{mg} / \mathrm{kg}, 20 \mathrm{mg} / \mathrm{kg}, 100 \mathrm{mg} / \mathrm{kg}$, i.p.) markedly increased Fos labeling within 90 min of injection in both Wt and Null animals compared with saline-injected controls ( $n=3$ for each group, Fig. 6). In both genotypes, Fos induction was strongest in the prelimbic, infralimbic, piriform, cingulate and retrosplenial cortices (Fig. 6). Quantitative analysis of Fos labeling in the piriform cortex revealed a dosedependent effect of ketamine on the number of Fos-positive cells in the Nulls, including restoration of Wt levels at higher doses (Null vehicle, $41.3 \pm 9.2$ cells; Null $8 \mathrm{mg} / \mathrm{kg}$ ketamine, $82.9 \pm 13.4$ cells; Null $20 \mathrm{mg} / \mathrm{kg}$ ketamine, $83.2 \pm 18.2$ cells; Null $100 \mathrm{mg} / \mathrm{kg}$ ketamine, $116.3 \pm 26.4$ cells; Wt vehicle, $99.5 \pm 13.3$ cells; Wt $100 \mathrm{mg} / \mathrm{kg}$ ketamine, $119.3 \pm 17.2$ cells; Fig. $6 C$ ). These data indicate that although Fos is downregulated in limbic forebrain structures in the absence of MeCP2, Fos expression remains plastic and subject to induction by factors that alter forebrain network activity.

\section{Ketamine rescues abnormal PPI of acoustic startle in Mecp2 Hets}

PPI of the ASR is a measure of sensorimotor gating and is widely used as an index of cognitive function in neuropsychiatric disorders, including ASDs (McAlonan et al., 2002; Frankland et al., 2004; Perry et al., 2007; Yuhas et al., 2011). PPI measures the ability of a weak sensory input to modulate behavioral responses to a subsequent strong sensory stimulus and thereby reflects the function of inhibitory circuitry thought to be critical for normal cognition. Because the circuitry underlying PPI includes structures that exhibit reduced Fos staining in Nulls, such as the mPFC and nAC (Swerdlow et al., 2001; Alsene et al., 2011), and because ketamine treatment of Nulls rescues Fos expression in these regions, we decided to use PPI as an index of forebrain circuit function in the absence and presence of ketamine. Heterozygous female Mecp2 mutants (Hets) were used for these experiments because acoustic startle measurements can be unreliable in Nulls due to their relatively small size. Although, as described by others, overall levels of Fos expression are lower in females compared with males (Westenbroek et al., 2003), Fos was significantly reduced in the Het forebrain compared with $\mathrm{Wt}$, as in male Nulls (Table 6).

PPI was compared in vehicle- and drug-treated Hets and ageand sex-matched Wt animals, using a sub-psychotomimetic dose of ketamine $(8 \mathrm{mg} / \mathrm{kg} ; n=9$ for Wt vehicle and ketamine, $n=8$
Table 6. Quantification of Fos expression in selected brain regions of female Wt vs Het mice

\begin{tabular}{lcc}
\hline Forebrain & Female Wt $(n=11)$ & Female Het $(n=9)$ \\
\hline Piriform cortex & $41.4 \pm 3.7$ & $31.8 \pm 5.6^{\#}$ \\
Nucleus accumbens & $48.8 \pm 3.4$ & $25.5 \pm 5.6^{* *}$ \\
Cingulate cortex & $28.3 \pm 6.6$ & $26.1 \pm 5.7$ \\
Retrosplenial cortex & $7.4 \pm 1.9$ & $1.4 \pm 0.3^{*}$ \\
Prelimbic cortex & $28.5 \pm 6.3$ & $10.3 \pm 2.9^{*}$ \\
Infralimbic cortex & $21.8 \pm 5.5$ & $10.8 \pm 2.3^{\#}$ \\
\hline
\end{tabular}

Data are displayed as mean \pm SEM $\left({ }^{*} p<0.05 ;{ }^{* *} p<0.01 ;{ }^{\#} p<0.15\right)$.

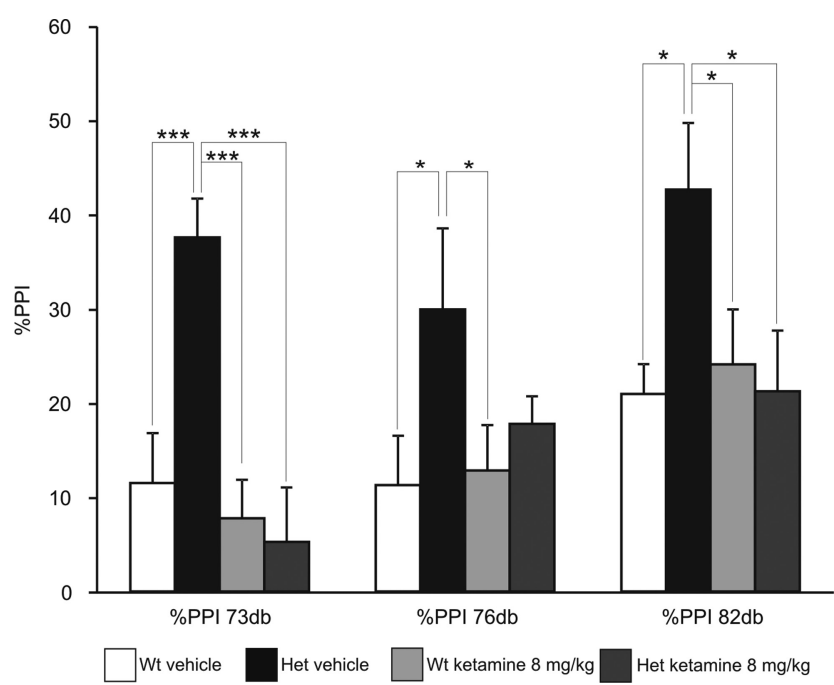

Figure 7. Het mice exhibit abnormal prepulse inhibition of acoustic startle which is restored to Wt levels by acute treatment with a sub-psychotomimetic dose of ketamine. Het mice exhibit a significant increase in PPI amplitude at 11 weeks of age that is restored to Wt levels by acute treatment with ketamine at $8 \mathrm{mg} / \mathrm{kg} .{ }^{*} p<0.05 ;{ }^{* * *} p<0.001$.

for Het vehicle and ketamine). Vehicle-treated Hets exhibited a significant increase in PPI amplitude compared with vehicletreated Wt at all levels of prepulse tested (\%PPI $73 \mathrm{~dB} ; \mathrm{Wt}, 11.5 \pm$ 5.3, Het, $37.6 \pm 4.1, p<0.001$; \%PPI $76 \mathrm{~dB}$; Wt, $11.3 \pm 5.2$, Het, $29.9 \pm 8.6, p<0.05 ; \%$ PPI $82 \mathrm{~dB}$; Wt, $20.9 \pm 3.2$, Het, $42.6 \pm 7.1$, $p<0.05$; Fig. 7). Acoustic startle by itself was not different among groups (Startle amplitude; Wt vehicle, $974.8 \pm 109.8$; Het vehicle, $759.6 \pm 73.7)$. Acute treatment with ketamine restored PPI in Hets to Wt levels (Het ketamine, \%PPI $73 \mathrm{~dB}, 5.3 \pm 5.8$; \%PPI 76 $\mathrm{dB}, 17.8 \pm 2.9$; \%PPI $82 \mathrm{~dB}, 21.4 \pm 6.4$, Fig. 7 ), whereas ketamine treatment did not alter PPI in Wt (Wt ketamine, \%PPI $73 \mathrm{~dB}$, $7.8 \pm 4.1 ; \%$ PPI $76 \mathrm{~dB}, 12.8 \pm 4.8 ; \%$ PPI $82 \mathrm{~dB}, 24.1 \pm 5.8$; Fig. 7$)$ and had no effect on acoustic startle alone (Wt ketamine, 798.6 \pm 106.3; Het ketamine, $862.7 \pm 149.5)$.

\section{Discussion}

Our findings demonstrate marked effects of Mecp2 genotype on expression of the activity-dependent, immediate-early gene product Fos within specific forebrain and hindbrain networks, including many previously unrecognized sites of circuit dysfunction within the Mecp2 mutant brain. In view of the close spatial and temporal association between genotype effects on neural activity and Fos expression, our data indicate that loss of MeCP2 results in a stereotyped pattern of activity changes within a defined subset of functionally interrelated brain circuits that emerges during late postnatal development, coincident with the appearance of overt symptoms (Fig. 8; Table 1). 


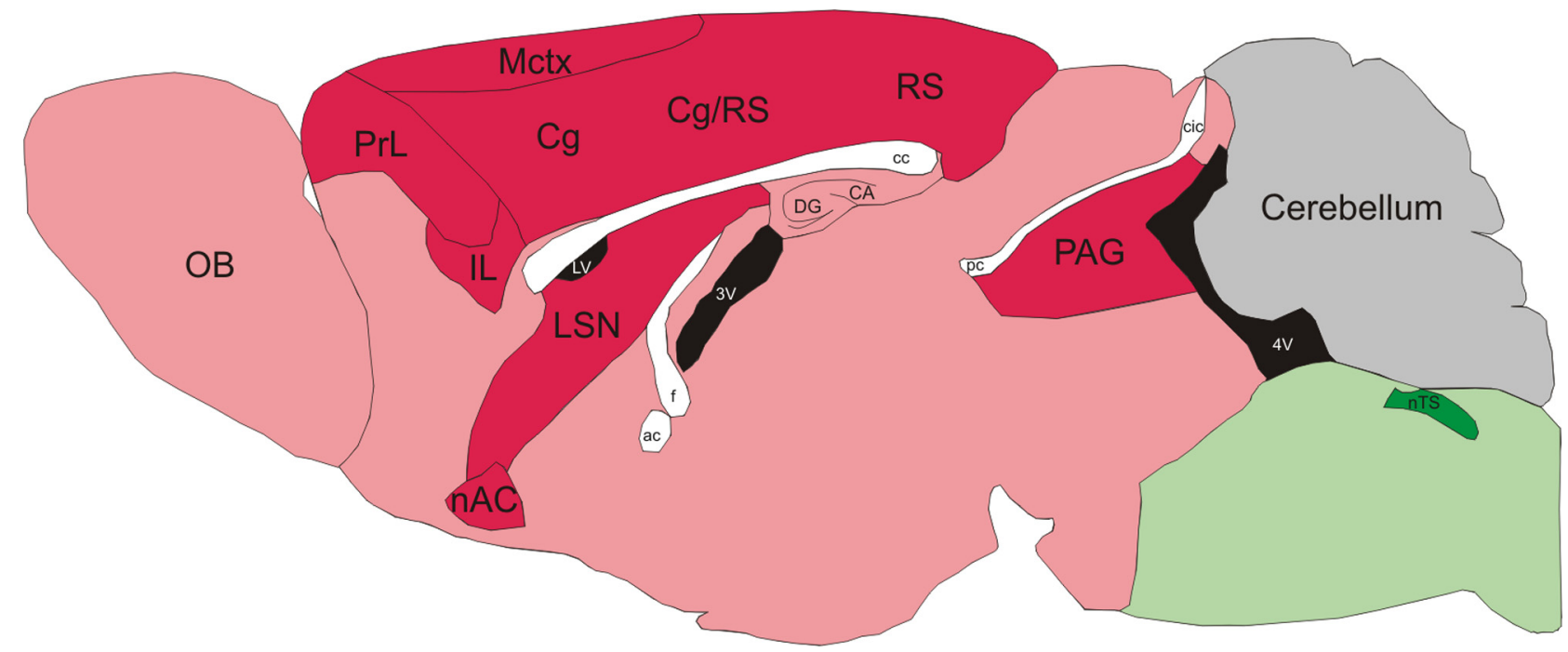

Figure 8. Summary map of Mecp2 genotype effects on Fos expression. Differences in Fos expression in the Null brain compared to Wt are color coded as follows: Red, Null < Wt; Green, Null $>$ Wt. Pink, Structures in this domain showed negligible Fos labeling or a nonsignificant trend of Null $<W t(p=0.051-0.52)$; light green, structures in this domain showed negligible Fos labeling or a nonsignificant trend of Null $>\mathrm{Wt}(p=0.051-0.200)$; Gray, no apparent difference (not quantified). White delineates fiber tracts and black shading indicates ventricles. 3V, Third ventricle; $4 \mathrm{~V}$, fourth ventricle; ac, anterior commissure; CA, cornu ammonis; cc, corpus callosum; Cg, cingulate; cic, commissure of the inferior colliculus; DG, dentate gyrus; f, fornix; IL, infralimbic cortex; LSN, lateral septal nuclei; LV, lateral ventricle; Mctx, motor cortex; $n A C$, nucleus accumbens; $n T S$, nucleus of the solitary tract; $0 B$, olfactory bulb; PAG, periaqueductal gray; $p c$, posterior commissure; Pn, pontine nucleus; PrL, prelimbic cortex; RS, retrosplenial cortex.

\section{Forebrain circuitry and the default mode network}

Reduced expression of Fos in forebrain cortices is consistent with reports of hypoconnectivity in layer 5 cortical circuits in Mecp2 mutants (for review, see Shepherd and Katz, 2011). However, a particularly striking feature of the Fos map in Null mice is the marked reduction in labeling throughout the midline limbic network, including the medial prefrontal (mPFC), cingulate and retrosplenial cortices compared with Wt (Fig. 8). This pattern of hypoactivity is significant because (1) these cortices are key nodes in the default mode network, a forebrain meta-circuit that also exhibits hypoactivity and/or reduced connectivity in human autism (for review, see Minshew and Keller, 2010), and (2) the midline limbic cortices play a critical role in behavioral state regulation of autonomic homeostasis, which is abnormal in RTT. We also found reduced Fos activity in sensory cortices which, in humans, interact with the default mode network through a frontoparietal control system (Vincent et al., 2008) that includes the dorsal PFC and cingulate cortex. The default mode network is considered critical for self-referential cognition and theory of mind (Gusnard et al., 2001; Raichle et al., 2001; Buckner et al., 2008), planning, remembering, and monitoring the external environment (Gilbert et al., 2007; Hahn et al., 2007). Social deficits in ASDs have been correlated with weaker connections between the cingulate and frontal/temporal cortices, while stereotyped and repetitive behaviors are correlated with weaker connections between the cingulate cortex and the mPFC (Weng et al., 2010). The fact that Mecp2 mutants exhibit reduced Fos expression in these structures suggests that hypoactivity in the default mode network may be a common feature of RTT and nonsyndromic autism and may underlie overlapping features of behavioral dysfunction in these disorders.

We also observed significant decreases in Fos labeling in the Null piriform, visual, somatosensory, auditory and motor cortices, as well as the nucleus accumbens, septal nuclei, and the caudate/putamen. Although further work is needed to fully understand the relationship between reduced activity in these structures and specific functional abnormalities, hypoactivity in motor cortex and the basal ganglia correlates well with the hypokinesis characteristic of young RTT patients and mouse models (Chahrour and Zoghbi, 2007). On the other hand, we saw no significant effect of Mecp2 genotype on Fos expression in the hippocampus, a region which is prone to network hyperexcitability in vitro (Moretti et al., 2006; Zhang et al., 2008; Fischer et al., 2009; Calfa et al., 2011; Nelson et al., 2011). It is possible, however, that genotype effects on Fos expression in the Null hippocampus would be detectable in the context of stimuli that trigger seizure activity, given that, in some studies, hyperexcitability in hippocampal networks is only apparent after challenge with excitatory stimuli (Zhang et al., 2008). It is also possible that this apparent discrepancy reflects differences in network excitability between intact animals and in vitro preparations as observed previously (Zhang et al., 2008; D'Cruz et al., 2010).

\section{Ketamine rescue of mutant Fos and PPI phenotypes}

Our finding that forebrain deficits in Fos expression in Nulls can be rescued by acute treatment with ketamine, even at subpsychotomimetic doses, supports the hypothesis that reduced Fos labeling reflects a reversible deficit in network activity, rather than an intrinsic inability to express Fos. Ketamine has previously been shown to increase Fos in the rodent forebrain by disinhibiting cortical pyramidal cells (Behrens et al., 2007); proposed mechanisms include antagonism of NMDA receptors and interaction with $\sigma$ receptors (Nakao et al., 2002, 2003). Thus, the recovery of Fos expression in ketamine-treated Nulls likely reflects a restoration of excitatory drive in circuits that are otherwise hypoactive in the absence of MeCP2. Indeed, in preliminary experiments we observed that Fos is often colocalized with CaMKII, a marker of cortical excitatory neurons, and is not expressed by parvalbumin-positive interneurons. Moreover, the fact that ketamine also reduces mutant PPI to Wt levels indicates that this treatment is also effective at restoring circuit function in $\mathrm{MeCP} 2$ deficient mice. Although the specific site(s) at which ketamine acts to restore Wt PPI in Hets remain to be defined, there is overlap between structures involved in cortical modulation of 
PPI and those exhibiting Fos rescue in ketamine-treated animals, including the mPFC and nAC (Swerdlow et al., 2001; Alsene et al., 2011). It is also possible that the rescue of PPI is related to the ability of ketamine to acutely increase translation of brainderived neurotrophic factor (BDNF) (Autry et al., 2011), as BDNF levels are reduced in Mecp2 mutants compared with Wt controls (Schmid et al., 2012), and PPI amplitude has previously been shown to be inversely related to BDNF availability (Takahashi et al., 2006; Papaleo et al., 2011). Regardless of mechanism, these data highlight the potential of low-dose ketamine treatment to improve behavioral dysfunction in RTT, as in other neuropsychiatric disorders (Autry et al., 2011).

\section{Circuits for autonomic homeostasis}

Consistent with the pathophysiology of RTT, our data indicate circuit dysfunction in structures involved in both reflex and behavioral control of cardiorespiratory function, including the medulla (nTS), midbrain (PAG) and forebrain limbic cortices in Nulls. Because RTT patients exhibit complex disturbances of breathing and heart rate control (Katz et al., 2009), attention has focused on nTS as a possible locus at which loss of MeCP2 deranges cardiorespiratory homeostasis. Indeed, the present findings, together with previous work from our laboratory (Kline et al., 2010), demonstrate that loss of MeCP2 is associated with synaptic hyperexcitability in symptomatic mice in all three of the principal nTS subnuclei involved in regulating cardiorespiratory reflex integration (nComm, lnTS, mnTS). Synaptic hyperexcitability in Nulls appears to result in part from a failure to undergo a developmental decline in eEPSC amplitude that normally occurs between 3 and 6 weeks. A similar persistence of immature circuit properties has recently been described in the Mecp2 Null hippocampus (Calfa et al., 2011). Together, these observations indicate a requirement for $\mathrm{MeCP} 2$ in differentiation of mature functional neuronal properties during late postnatal development.

Our electrophysiological and Fos mapping data indicate a shift toward a more excited default state in cardiorespiratory subnuclei in the mutant nTS, which would be expected to result in a loss of sensory gating within nTS and destabilization of cardiorespiratory homeostasis. In fact, Mecp 2 mutant mice exhibit an exaggerated hypoxic ventilatory reflex (Bissonnette and Knopp, 2006; Roux et al., 2008; Voituron et al., 2009; Ward et al., 2011), a homeostatic increase in ventilation triggered by primary chemoafferent inputs to the nComm (Finley and Katz, 1992; Chitravanshi and Sapru, 1995). Similarly, hyperexcitability at the first synapse in $\operatorname{lnTS}$, where pulmonary stretch receptors terminate (Davies et al., 1987; Kubin et al., 2006), would be expected to lower the activation threshold for the Hering Breuer reflex pathway, which inhibits inspiration and promotes expiration. Indeed, Mecp2 mutants exhibit prolonged respiratory pauses in response to vagal stimulation (Stettner et al., 2007), indicative of exaggerated Hering Breuer reflex activation. Our data therefore highlight the $\operatorname{lnTS}$ as a key site at which synaptic hyperexcitability likely contributes to the frequent respiratory pauses that characterize breathing in Mecp2 mutants and RTT patients. Because cardiorespiratory control is adjusted continuously to meet metabolic and behavioral needs, reduced gating of primary afferent input to nTS could well underlie the unpredictable fluctuations in respiratory pattern formation and cardiac control seen in RTT patients.

However, sensory gating deficits at the level of nTS cannot explain all of the cardiorespiratory phenotypes associated with loss of $\mathrm{MeCP} 2$ function. In particular, cardiorespiratory dysfunc- tion in RTT patients is also dependent on behavioral state, with symptoms improving during sleep (Weese-Mayer et al., 2008) and worsening in the context of emotional stress (Kerr and Julu, 1999). Thus, it is particularly noteworthy that Nulls exhibit reduced Fos levels in interconnected forebrain and midbrain structures critical for behavioral modulation of respiration, including the mPFC, cingulate cortex (Evans et al., 2009) and the vlPAG (Subramanian et al., 2004). Our data, indicating hypoactivity in limbic cortices that project to the vlPAG, and hyperactivity in the nTS, a downstream target of the vlPAG (Fisk and Wyss, 2000; Huang et al., 2000; Vertes, 2004; Subramanian and Holstege, 2010), suggest that excitatory/inhibitory imbalance across the forebrain-midbrain-hindbrain neuraxis may well be a substrate for abnormal behavioral state regulation of respiratory and autonomic homeostasis in RTT. Studies in progress are directed at determining whether or not ketamine and other agents can correct this imbalance and restore normal state dependent modulation of autonomic function in RTT mice.

\section{References}

Alsene KM, Rajbhandari AK, Ramaker MJ, Bakshi VP (2011) Discrete forebrain neuronal networks supporting noradrenergic regulation of sensorimotor gating. Neuropsychopharmacology 36:1003-1014. CrossRef Medline

Amir RE, Van den Veyver IB, Wan M, Tran CQ, Francke U, Zoghbi HY (1999) Rett syndrome is caused by mutations in X-linked MECP2, encoding methyl-CpG-binding protein 2. Nat Genet 23:185-188. CrossRef Medline

Andresen MC, Kunze DL (1994) Nucleus tractus solitarius-gateway to neural circulatory control. Annu Rev Physiol 56:93-116. CrossRef Medline

Andresen MC, Peters JH (2008) Comparison of baroreceptive to other afferent synaptic transmission to the medial solitary tract nucleus. Am J Physiol Heart Circ Physiol 295:H2032-H2042. CrossRef Medline

Armstrong DD (2005) Neuropathology of Rett syndrome. J Child Neurol 20:747-753. CrossRef Medline

Autry AE, Adachi M, Nosyreva E, Na ES, Los MF, Cheng PF, Kavalali ET, Monteggia LM (2011) NMDA receptor blockade at rest triggers rapid behavioural antidepressant responses. Nature 475:91-95. CrossRef Medline

Behrens MM, Ali SS, Dao DN, Lucero J, Shekhtman G, Quick KL, Dugan LL (2007) Ketamine-induced loss of phenotype of fast-spiking interneurons is mediated by NADPH-oxidase. Science 318:1645-1647. CrossRef Medline

Bissonnette JM, Knopp SJ (2006) Separate respiratory phenotypes in methyl-CpG-binding protein 2 (Mecp2) deficient mice. Pediatr Res 59: 513-518. CrossRef Medline

Broyd SJ, Demanuele C, Debener S, Helps SK, James CJ, Sonuga-Barke EJ (2009) Default-mode brain dysfunction in mental disorders: a systematic review. Neurosci Biobehav Rev 33:279-296. CrossRef Medline

Buckner RL, Andrews-Hanna JR, Schacter DL (2008) The brain's default network: anatomy, function, and relevance to disease. Ann N Y Acad Sci 1124:1-38. CrossRef Medline

Calfa G, Hablitz JJ, Pozzo-Miller L (2011) Network hyperexcitability in hippocampal slices from Mecp2 mutant mice revealed by voltage-sensitive dye imaging. J Neurophysiol 105:1768-1784. CrossRef Medline

Chahrour M, Zoghbi HY (2007) The story of Rett syndrome: from clinic to neurobiology. Neuron 56:422-437. CrossRef Medline

Chen RZ, Akbarian S, Tudor M, Jaenisch R (2001) Deficiency of methylCpG binding protein-2 in CNS neurons results in a Rett-like phenotype in mice. Nat Genet 27:327-331. CrossRef Medline

Chitravanshi VC, Sapru HN (1995) Chemoreceptor-sensitive neurons in commissural subnucleus of nucleus tractus solitarius of the rat. Am J Physiol 268:R851-R858. Medline

Dani VS, Nelson SB (2009) Intact LTP but reduced connectivity between neocortical layer 5 pyramidal neurons in a mouse model of Rett syndrome. J Neurosci 29:11263-11270. CrossRef Medline

Dani VS, Chang Q, Maffei A, Turrigiano GG, Jaenisch R, Nelson SB (2005) Reduced cortical activity due to a shift in the balance between excitation 
and inhibition in a mouse model of Rett syndrome. Proc Natl Acad Sci U S A 102:12560-12565. CrossRef Medline

Davies RO, Kubin L, Pack AI (1987) Pulmonary stretch receptor relay neurones of the cat: location and contralateral medullary projections. J Physiol 383:571-585. Medline

D'Cruz JA, Wu C, Zahid T, El-Hayek Y, Zhang L, Eubanks JH (2010) Alterations of cortical and hippocampal EEG activity in MeCP2-deficient mice. Neurobiol Dis 38:8-16. CrossRef Medline

Doyle MW, Andresen MC (2001) Reliability of monosynaptic sensory transmission in brain stem neurons in vitro. J Neurophysiol 85:22132223. Medline

Dragunow M, Faull R (1989) The use of c-fos as a metabolic marker in neuronal pathway tracing. J Neurosci Methods 29:261-265. CrossRef Medline

Evans KC, Dougherty DD, Schmid AM, Scannell E, McCallister A, Benson H, Dusek JA, Lazar SW (2009) Modulation of spontaneous breathing via limbic/paralimbic-bulbar circuitry: an event-related fMRI study. Neuroimage 47:961-971. CrossRef Medline

Faul F, Erdfelder E, Lang AG, Buchner A (2007) G*Power 3: a flexible statistical power analysis program for the social, behavioral, and biomedical sciences. Behav Res Methods 39:175-191. CrossRef Medline

Ferrara P, Andermarcher E, Bossis G, Acquaviva C, Brockly F, Jariel-Encontre I, Piechaczyk M (2003) The structural determinants responsible for c-Fos protein proteasomal degradation differ according to the conditions of expression. Oncogene 22:1461-1474. CrossRef Medline

Finley JC, Katz DM (1992) The central organization of carotid body afferent projections to the brainstem of the rat. Brain Res 572:108-116. CrossRef Medline

Fischer M, Reuter J, Gerich FJ, Hildebrandt B, Hägele S, Katschinski D, Müller M (2009) Enhanced hypoxia susceptibility in hippocampal slices from a mouse model of Rett syndrome. J Neurophysiol 101:1016-1032. CrossRef Medline

Fisk GD, Wyss JM (2000) Descending projections of infralimbic cortex that mediate stimulation-evoked changes in arterial pressure. Brain Res 859: 83-95. CrossRef Medline

Frankland PW, Wang Y, Rosner B, Shimizu T, Balleine BW, Dykens EM, Ornitz EM, Silva AJ (2004) Sensorimotor gating abnormalities in young males with fragile X syndrome and Fmr1-knockout mice. Mol Psychiatry 9:417-425. CrossRef Medline

Gilbert SJ, Dumontheil I, Simons JS, Frith CD, Burgess PW (2007) Comment on "Wandering minds: the default network and stimulusindependent thought". Science 317:43; author reply 43. CrossRef Medline

Gusnard DA, Akbudak E, Shulman GL, Raichle ME (2001) Medial prefrontal cortex and self-referential mental activity: relation to a default mode of brain function. Proc Natl Acad Sci U S A 98:4259-4264. CrossRef Medline

Hagberg B, Aicardi J, Dias K, Ramos O (1983) A progressive syndrome of autism, dementia, ataxia, and loss of purposeful hand use in girls: Rett's syndrome: report of 35 cases. Ann Neurol 14:471-479. CrossRef Medline

Hahn B, Ross TJ, Stein EA (2007) Cingulate activation increases dynamically with response speed under stimulus unpredictability. Cereb Cortex 17:1664-1671. CrossRef Medline

Haznedar MM, Buchsbaum MS, Wei TC, Hof PR, Cartwright C, Bienstock CA, Hollander E (2000) Limbic circuitry in patients with autism spectrum disorders studied with positron emission tomography and magnetic resonance imaging. Am J Psychiatry 157:1994-2001. CrossRef Medline

Huang ZG, Subramanian SH, Balnave RJ, Turman AB, Moi Chow C (2000) Roles of periaqueductal gray and nucleus tractus solitarius in cardiorespiratory function in the rat brainstem. Respir Physiol 120:185-195. CrossRef Medline

Inta D, Trusel M, Riva MA, Sprengel R, Gass P (2009) Differential c-Fos induction by different NMDA receptor antagonists with antidepressant efficacy: potential clinical implications. Int J Neuropsychopharmacol 12: 1133-1136. CrossRef Medline

Julu PO, Kerr AM, Apartopoulos F, Al-Rawas S, Engerström IW, Engerström L, Jamal GA, Hansen S (2001) Characterisation of breathing and associated central autonomic dysfunction in the Rett disorder. Arch Dis Child 85:29-37. CrossRef Medline

Katz DM, Dutschmann M, Ramirez JM, Hilaire G (2009) Breathing disorders in Rett syndrome: progressive neurochemical dysfunction in the respiratory network after birth. Respir Physiol Neurobiol 168:101-108. CrossRef Medline
Kennedy DP, Courchesne E (2008) Functional abnormalities of the default network during self- and other-reflection in autism. Soc Cogn Affect Neurosci 3:177-190. CrossRef Medline

Kerr AM, Julu PO (1999) Recent insights into hyperventilation from the study of Rett syndrome. Arch Dis Child 80:384-387. CrossRef Medline

Kline DD, Takacs KN, Ficker E, Kunze DL (2002) Dopamine modulates synaptic transmission in the nucleus of the solitary tract. J Neurophysiol 88:2736-2744. CrossRef Medline

Kline DD, Ogier M, Kunze DL, Katz DM (2010) Exogenous brain-derived neurotrophic factor rescues synaptic dysfunction in Mecp2-null mice. J Neurosci 30:5303-5310. CrossRef Medline

Kron M, Zimmermann JL, Dutschmann M, Funke F, Müller M (2011) Altered responses of MeCP2-deficient mouse brain stem to severe hypoxia. J Neurophysiol 105:3067-3079. CrossRef Medline

Kubin L, Alheid GF, Zuperku EJ, McCrimmon DR (2006) Central pathways of pulmonary and lower airway vagal afferents. J Appl Physiol 101:618627. CrossRef Medline

McAlonan GM, Daly E, Kumari V, Critchley HD, van Amelsvoort T, Suckling J, Simmons A, Sigmundsson T, Greenwood K, Russell A, Schmitz N, Happe F, Howlin P, Murphy DG (2002) Brain anatomy and sensorimotor gating in Asperger's syndrome. Brain 125:1594-1606. CrossRef Medline

Medrihan L, Tantalaki E, Aramuni G, Sargsyan V, Dudanova I, Missler M, Zhang W (2008) Early defects of GABAergic synapses in the brain stem of a MeCP2 mouse model of Rett syndrome. J Neurophysiol 99:112-121. CrossRef Medline

Minshew NJ, Keller TA (2010) The nature of brain dysfunction in autism: functional brain imaging studies. Curr Opin Neurol 23:124-130. CrossRef Medline

Monk CS, Peltier SJ, Wiggins JL, Weng SJ, Carrasco M, Risi S, Lord C (2009) Abnormalities of intrinsic functional connectivity in autism spectrum disorders. Neuroimage 47:764-772. CrossRef Medline

Moretti P, Levenson JM, Battaglia F, Atkinson R, Teague R, Antalffy B, Armstrong D, Arancio O, Sweatt JD, Zoghbi HY (2006) Learning and memory and synaptic plasticity are impaired in a mouse model of Rett syndrome. J Neurosci 26:319-327. CrossRef Medline

Nakao S, Miyamoto E, Masuzawa M, Kambara T, Shingu K (2002) Ketamine-induced c-Fos expression in the mouse posterior cingulate and retrosplenial cortices is mediated not only via NMDA receptors but also via sigma receptors. Brain Res 926:191-196. CrossRef Medline

Nakao S, Nagata A, Miyamoto E, Masuzawa M, Murayama T, Shingu K (2003) Inhibitory effect of propofol on ketamine-induced c-Fos expression in the rat posterior cingulate and retrosplenial cortices is mediated by GABAA receptor activation. Acta Anaesthesiol Scand 47:284-290. CrossRef Medline

Nelson ED, Bal M, Kavalali ET, Monteggia LM (2011) Selective impact of $\mathrm{MeCP} 2$ and associated histone deacetylases on the dynamics of evoked excitatory neurotransmission. J Neurophysiol 106:193-201. CrossRef Medline

Papaleo F, Silverman JL, Aney J, Tian Q, Barkan CL, Chadman KK, Crawley JN (2011) Working memory deficits, increased anxiety-like traits, and seizure susceptibility in BDNF overexpressing mice. Learn Mem 18:534544. CrossRef Medline

Perry W, Minassian A, Lopez B, Maron L, Lincoln A (2007) Sensorimotor gating deficits in adults with autism. Biol Psychiatry 61:482-486. CrossRef Medline

Raichle ME, MacLeod AM, Snyder AZ, Powers WJ, Gusnard DA, Shulman GL (2001) A default mode of brain function. Proc Natl Acad Sci U S A 98:676-682. CrossRef Medline

Roux JC, Dura E, Villard L (2008) Tyrosine hydroxylase deficit in the chemoafferent and the sympathoadrenergic pathways of the Mecp2 deficient mouse. Neurosci Lett 447:82-86. CrossRef Medline

Schmid DA, Yang T, Ogier M, Adams I, Mirakhur Y, Wang Q, Massa SM, Longo FM, Katz DM (2012) A TrkB small molecule partial agonist rescues TrkB phosphorylation deficits and improves respiratory function in a mouse model of Rett syndrome. J Neurosci 32:1803-1810. CrossRef Medline

Shepherd GM, Katz DM (2011) Synaptic microcircuit dysfunction in genetic models of neurodevelopmental disorders: focus on Mecp2 and Met. Curr Opin Neurobiol 21:827-833. CrossRef Medline

Steffenburg U, Hagberg G, Hagberg B (2001) Epilepsy in a representative series of Rett syndrome. Acta Paediatr 90:34-39. CrossRef Medline 
Stettner GM, Huppke P, Brendel C, Richter DW, Gärtner J, Dutschmann M (2007) Breathing dysfunctions associated with impaired control of postinspiratory activity in Mecp2-/y knockout mice. J Physiol 579:863-876. CrossRef Medline

Subramanian HH, Holstege G (2010) Periaqueductal gray control of breathing. Adv Exp Med Biol 669:353-358. CrossRef Medline

Subramanian HH, Balnave RJ, Chow CM (2004) Behavioural control of breathing in mammals: role of the midbrain periaqueductal gray. Adv Exp Med Biol 551:135-141. CrossRef Medline

Subramanian HH, Balnave RJ, Holstege G (2008) The midbrain periaqueductal gray control of respiration. J Neurosci 28:12274-12283. CrossRef Medline

Swerdlow NR, Geyer MA, Braff DL (2001) Neural circuit regulation of prepulse inhibition of startle in the rat: current knowledge and future challenges. Psychopharmacology (Berl) 156:194-215. CrossRef Medline

Takahashi M, Kakita A, Futamura T, Watanabe Y, Mizuno M, Sakimura K, Castren E, Nabeshima T, Someya T, Nawa H (2006) Sustained brainderived neurotrophic factor upregulation and sensorimotor gating abnormality induced by postnatal exposure to phencyclidine: comparison with adult treatment. J Neurochem 99:770-780. CrossRef Medline

Taneja P, Ogier M, Brooks-Harris G, Schmid DA, Katz DM, Nelson SB (2009) Pathophysiology of locus ceruleus neurons in a mouse model of Rett syndrome. J Neurosci 29:12187-12195. CrossRef Medline

Vertes RP (2004) Differential projections of the infralimbic and prelimbic cortex in the rat. Synapse 51:32-58. CrossRef Medline

Vincent JL, Kahn I, Snyder AZ, Raichle ME, Buckner RL (2008) Evidence for a frontoparietal control system revealed by intrinsic functional connectivity. J Neurophysiol 100:3328-3342. CrossRef Medline

Voituron N, Zanella S, Menuet C, Dutschmann M, Hilaire G (2009) Early breathing defects after moderate hypoxia or hypercapnia in a mouse model of Rett syndrome. Respir Physiol Neurobiol 168:109-118. CrossRef Medline
Ward CS, Arvide EM, Huang TW, Yoo J, Noebels JL, Neul JL (2011) MeCP2 is critical within HoxB1-derived tissues of mice for normal lifespan. J Neurosci 31:10359-10370. CrossRef Medline

Weese-Mayer DE, Lieske SP, Boothby CM, Kenny AS, Bennett HL, Silvestri JM, Ramirez JM (2006) Autonomic nervous system dysregulation: breathing and heart rate perturbation during wakefulness in young girls with Rett syndrome. Pediatr Res 60:443-449. CrossRef Medline

Weese-Mayer DE, Lieske SP, Boothby CM, Kenny AS, Bennett HL, Ramirez JM (2008) Autonomic dysregulation in young girls with Rett Syndrome during nighttime in-home recordings. Pediatr Pulmonol 43:1045-1060. CrossRef Medline

Weng SJ, Wiggins JL, Peltier SJ, Carrasco M, Risi S, Lord C, Monk CS (2010) Alterations of resting state functional connectivity in the default network in adolescents with autism spectrum disorders. Brain Res 1313:202-214. CrossRef Medline

Westenbroek C, Den Boer JA, Ter Horst GJ (2003) Gender-specific effects of social housing on chronic stress-induced limbic Fos expression. Neuroscience 121:189-199. CrossRef Medline

Wood L, Shepherd GM (2010) Synaptic circuit abnormalities of motorfrontal layer $2 / 3$ pyramidal neurons in a mutant mouse model of Rett syndrome. Neurobiol Dis 38:281-287. CrossRef Medline

Wood L, Gray NW, Zhou Z, Greenberg ME, Shepherd GM (2009) Synaptic circuit abnormalities of motor-frontal layer $2 / 3$ pyramidal neurons in an RNA interference model of methyl-CpG-binding protein 2 deficiency. J Neurosci 29:12440-12448. CrossRef Medline

Yuhas J, Cordeiro L, Tassone F, Ballinger E, Schneider A, Long JM, Ornitz EM, Hessl D (2011) Brief report: Sensorimotor gating in idiopathic autism and autism associated with fragile X syndrome. J Autism Dev Disord 41:248-253. CrossRef Medline

Zhang L, He J, Jugloff DG, Eubanks JH (2008) The MeCP2-null mouse hippocampus displays altered basal inhibitory rhythms and is prone to hyperexcitability. Hippocampus 18:294-309. CrossRef Medline 